\title{
The Application of Small Molecules to the Control of Typical Species Associated With Oral Infectious Diseases
}

OPEN ACCESS

Edited by:

Prasanna Neelakantan, The University of Hong Kong,

Hong Kong SAR, China

Reviewed by:

Hua Xie,

Meharry Medical College,

United States

Armelia Sari Widyarman,

Trisakti University, Indonesia

Xuan Li,

The University of Hong Kong,

Hong Kong SAR, China

${ }^{*}$ Correspondence:

Ran Yang

yangran@scu.edu.cn

Xin Xu

xin.xu@scu.edu.cn

${ }^{\dagger}$ These authors have contributed equally to this work

Specialty section:

This article was submitted to Microbiome in Health and Disease,

a section of the journal

Frontiers in Cellular and

Infection Microbiology

Received: 16 November 2021 Accepted: 28 January 2022

Published: 21 February 2022

Citation:

Yang S, Lyu X, Zhang J, Shui Y, Yang $R$ and $X u X$ (2022) The Application of Small Molecules to the Control of Typical Species Associated With Oral Infectious Diseases. Front. Cell. Infect. Microbiol. 12:816386.

do: 10.3389/fcimb.2022.816386

\begin{abstract}
Sirui Yang ${ }^{1,2 \dagger}$, Xiaoying $\mathrm{Lyu}^{1 \dagger}$, Jin Zhang ${ }^{1,2}$, Yusen Shui ${ }^{1}$, Ran Yang ${ }^{1,3 *}$ and $\mathrm{Xin} \mathrm{Xu}^{1,2 *}$
1 State Key Laboratory of Oral Diseases, National Clinical Research Center for Oral Diseases, West China Hospital of Stomatology, Sichuan University, Chengdu, China, ${ }^{2}$ Department of Cariology and Endodontics, West China Hospital of Stomatology, Sichuan University, Chengdu, China, ${ }^{3}$ Department of Pediatric Dentistry, West China Hospital of Stomatology, Sichuan University, Chengdu, China
\end{abstract}

Oral microbial dysbiosis is the major causative factor for common oral infectious diseases including dental caries and periodontal diseases. Interventions that can lessen the microbial virulence and reconstitute microbial ecology have drawn increasing attention in the development of novel therapeutics for oral diseases. Antimicrobial small molecules are a series of natural or synthetic bioactive compounds that have shown inhibitory effect on oral microbiota associated with oral infectious diseases. Novel small molecules, which can either selectively inhibit keystone microbes that drive dysbiosis of oral microbiota or inhibit the key virulence of the microbial community without necessarily killing the microbes, are promising for the ecological management of oral diseases. Here we discussed the research progress in the development of antimicrobial small molecules and delivery systems, with a particular focus on their antimicrobial activity against typical species associated with oral infectious diseases and the underlying mechanisms.

Keywords: oral microbiota, small molecules, antimicrobial agents, dental plaque biofilm, dental caries, periodontal diseases

\section{INTRODUCTION}

The oral microbiota, including more than 700 microbial species, are the most complicated microbial communities in human body (Dewhirst et al., 2010). According to the ecological plaque hypothesis, oral microbial dysbiosis leads to the occurrence of oral infectious diseases including dental caries and periodontal diseases, which seriously endanger oral and general health (Theilade, 1986).

Streptococcus mutans is well recognized as the major cariogenic species due to its capability of adhesion to tooth surfaces, generation of acid through sugar fermentation, and tolerance and persistence in acidic microenvironment (Hamada et al., 1984; Banas, 2004; Bowen et al., 2018). Currently, the homeostasis between pathogenic and commensal bacteria has attracted increasing attention in the etiology and pathogenesis of dental caries. Dental caries is believed to be initiated by 
the imbalanced microecology and the overgrowth of acidogenic/ aciduric bacteria such as S. mutans (Tanner et al., 2016; Samaranayake and Matsubara, 2017). In addition to caries, the microbiological etiology of periodontitis has also been indicated in recent years (Riep et al., 2009). Porphyromonas gingivalis, Tannerella forsythia, and Treponema denticola, commonly known as the "red complex", are well recognized as the principal pathogens associated with periodontal destruction (Socransky et al., 1998). Currently, periodontitis is believed to be the consequence of a broadly-based dysbiotic alteration in periodontal microbiota, whereby some keystone species such as $P$. gingivalis triggers the development of this disease (Hajishengallis and Lamont, 2012). Candida albicans is a commensal fungal species colonizing human oral mucosal surfaces. In the immunocompromised individuals, C. albicans becomes opportunistic pathogen causing mucosal and disseminated infections (Metwalli et al., 2013). Intriguingly, $C$. albicans robustly interacts with oral bacteria, and this crosskingdom interaction enhances the virulence of both fungi and bacteria, and ultimately aggravates oral diseases (Dewhirst et al., 2010; Peters et al., 2012). It has been proven that C. albicans is closely involved in the occurrence of various oral diseases including early childhood caries, root caries, periodontitis, endodontic infections, oral mucositis and facial space infections (Krom et al., 2014).

As an adequate plaque control by mechanical means such as brushing and flossing is difficult to achieve by most patients, mouth rinses containing antimicrobial agents are considered as an effective adjuvant measure to control dental caries (Lim and Kam, 2008; Rath and Singh, 2013). Chlorhexidine (CHX) is widely used to control oral pathogens due to its robust antimicrobial activity and broad spectrum (Jones, 1997). However, CHX has drawbacks such as taste confusions, mucosal soreness, oral microbial dysbiosis and drug resistance, which limit its long-term application (Jones, 1997; Walsh et al., 2015). Bacterial drug resistance is one of the main threats to human health (Kumar and Balbach, 2017), limiting the options of clinical treatment for oral infectious diseases (Hegstad et al., 2010). Long-term use of $\mathrm{CHX}$ could cause microbial resistance in microbes, including Staphylococcus aureus, Enterococcus faecalis and Klebsiella pneumoniae (Wang et al., 2017). Therefore, novel agents are urgently needed to control oral infectious diseases. Antimicrobial small molecules are a series of natural or synthetic bioactive compounds showing good antimicrobial activity against microbiota associated with infectious diseases (Worthington et al., 2012). Small molecules can be developed via various approaches. Drug repurposing, drug screening from existing small-molecule libraries or natural resources, and target-based designing are most common approaches to the development of small molecules that target oral microbiota and consequently benefit oral infectious disease control. In this review, we aimed to discuss the research progress in the development of antimicrobial small molecules and delivery systems, with a particular focus on: 1) their antimicrobial activity against keystone bacteria including $S$. mutans, $P$. gingivalis and $C$. albicans; 2) their inhibitory effects on the pheromones that mediate interspecies communications within polymicrobial communities; 3 ) the research progress in the development of delivery systems that enhance the antimicrobial activity of small molecules in the management of oral infectious diseases.

\section{SMALL MOLECULES THAT INHIBIT KEYSTONE BACTERIA ASSOCIATED WITH ORAL INFECTIOUS DISEASES}

\section{Streptococcus mutans}

$S$. mutans is generally recognized as the key cariogenic species, particularly due to its capability of driving the shift of oral microbiota towards a more acidogenic/aciduric community that ultimately causes tooth demineralization and visible decay (Marsh, 2010).

Different small molecular antibiotics from natural products and synthetic compounds have been identified against $S$. mutans. Drugrepositioning is a commonly used approach to the identification of antimicrobial agents that inhibit $S$. mutans. Nitrofuran, with a mode of action similar to that of nitroimidazole, shows inhibitory activity on oral bacteria such as S. mutans and Enterococcus faecalis (Silva et al., 2014; Ang et al., 2017). Based on the antimicrobial activity of nitrofuran, our group synthesized and identified a compound named ZY354, a water-soluble hybrid of indolin-2-one and nitrofuran, which showed potent antimicrobial activity and selectivity against $S$. mutans compared with CHX (Zhang et al., 2019). Saputo et al. (2018) screened and identified 126 FDAapproved small molecules that exhibited antimicrobial activity against planktonic growth of $S$. mutans, among which 24 drugs inhibited biofilm formation, 6 drugs killed pre-existing biofilms, and 84 drugs exhibited both bacteriostatic and bactericidal effects against S. mutans biofilms. Napabucasin (NAP) is a phase III clinical trials anticancer drug with antibacterial activity against Escherichia coli, Streptococcus faecalis, and Staphylococcus aureus (Kuete et al., 2007; Kuete et al., 2011). Our group repurposed NAP against oral streptococci and found good antimicrobial activity of NAP against S. mutans biofilms (Kuang et al., 2020). Besides, NAP showed relatively lower antibacterial effect on oral streptococci than $\mathrm{CHX}$ with mild cytotoxicity on oral cells. We further redesigned and synthesized a novel small molecule based on NAP, namely LCGN25, which exhibited potent antibacterial activity, lessened cytotoxicity, and induced no drug resistance of cariogenic $S$. mutans (Lyu et al., 2021a). Chen et al. screened approximately 2600 compounds and identified an antagonist of calcium-sensing receptor, namely NPS-2143, which exhibited antimicrobial activity against methicillin-resistant $S$. aureus (MRSA) (Chen Y et al., 2019). Further modifications of NPS-2143 yield a compound II-6s (Chen Y et al., 2019). Our group demonstrated that II-6s effectively inhibited the growth of $S$. mutans, reduced EPS production and induced no drug resistance in $S$. mutans after repeated treatment as compared to $\mathrm{CHX}$, indicating its potential use in the control of dental caries (Zhang J et al., 2021).

Phenotypic screening is also a reliable approach to the identification of new antimicrobials. Antigen I/II, also known as Pac, mediates the sucrose-independent adhesion of S. mutans (Munro et al., 1993; Jenkinson and Demuth, 1997; Love et al., 1997), 
while Gtfs (GtfB, GtfC, and GtfD) mediate its sucrose-dependent adhesion (Bramstedt, 1968) and play an important role in the interspecies coaggregation and the development of oral biofilms (Bowen and Koo, 2011; Kim D et al., 2020). Rivera-Quiroga et al. performed a high-throughput screening of 883551 molecules, and identified three molecules, namely ZINC19835187 (ZI-187), ZINC19924939 (ZI-939) and ZINC 19924906 (ZI-906), which targeted antigen I/II and inhibited the adhesion of $S$. mutans with low cytotoxicity (Rivera-Quiroga et al., 2020). Wu et al. also screened and identified a molecule called 2A4, showing selectivity on S. mutans in multispecies biofilms via inhibiting antigens I/II and Gtfs (Liu et al., 2011). The same group also performed a structure-based virtual screening of 500,000 compounds against the $\mathrm{GtfC}$ catalytic domain and identified a lead compound, namely G43, which selectively bond Gtfc and significantly inhibited the biofilm formation and cariogenicity of S. mutans (Zhang et al., 2017). They further synthesized an analog of $\mathrm{G} 43$, named $\mathrm{III}_{\mathrm{F} 1}$, which remarkably reduced dental caries in rats (Nijampatnam et al., 2021). Ren et al. screened 15000 molecules based on the structure of GtfC protein domain and identified a quinoxaline derivative, 2-(4methoxyphenyl)-N-(3-\{[2-(4-methoxyphenyl)ethyl]imino\}-1,4dihydro-2-quinoxalinylidene)ethanamine, which selectively bond $\mathrm{GtfC}$, reduced the synthesis of insoluble glucans, inhibited S. mutans biofilm and reduced caries in rats (Ren et al., 2016). SrtA is membraned-bond transpeptidase that catalyzes surface protein antigen I/II, thus contributing to the biofilm formation of S. mutans (Lee and Boran, 2003; Krzysciak et al., 2014; Chen X et al., 2019; Wang et al., 2019). Recently, several SrtA inhibitors have been identified from either natural products or synthetic compounds (Park W et al., 2017; Song et al., 2017). Samanli et al. screened and identified a SrtA inhibitor, namely CHEMBL243796 (kurarinone), which showed better affinity to SrtA as compared to CHX (Salmanli et al., 2021). In addition to the aforementioned molecules that have been proven to inhibit antigen I/II and Gtfs, several synthetic molecules have been designed and showed antibacterial effects against $S$. mutans. Kim et al. synthesized a series of pyrimidinone or pyrimidindione-fused1,4-naphthoquinones with antibacterial effects via pharmacophore hybridization, and some derivatives exhibited notable bacteriostatic and bactericidal effects against S. mutans in both resistant and sensitive strains (Kim $\mathrm{K}$ et al., 2020). Zhang et al. screened 100 trimetrexate (TMQ) analogs and identified 3 compounds with good selectivity against $S$. mutans (Zhang et al., 2015). Garcia et al. screened a series of 2Aminoimidazole (2-AI) derivatives, and identified a small molecule 3F1, which specifically disturbed S. mutans biofilms and reduced caries in rats (Garcia et al., 2017). Besingi et al. screened and identified a benzoquinone derivative AA-861, which exhibited antibiofilm effects against $S$. mutans by targeting amyloid fibrils, an important scaffold in S. mutans biofilms (Besingi et al., 2017). Chen et al. also screened and identified a small molecule, namely D25, which targeted amyloid fibrils and selectively inhibited S. mutans biofilms (Chen et al., 2021).

Natural products and their derivatives also accounted for a large number of antimicrobial small molecules due to their structural diversity and biological activity (Davison and Brimble, 2019; Newman and Cragg, 2020). The tea polyphenols epigallocatechin gallate (EGCG) has been identified to inhibit $S$. mutans for decades. EGCG not only inhibits planktonic bacteria but also reduces the biofilm formation of $S$. mutans by inhibiting Gtfs. In addition, EGCG can inhibit lactate dehydrogenase and $\mathrm{F}_{1} \mathrm{~F}_{0}$-ATPase, and thus reduces the acidogenicity and aciduricity of $S$. mutans (Xu et al., 2011; Xu et al., 2012; Hairul Islam et al., 2020). A lipid-soluble green tea polyphenols which is designed based on EGCG, namely epigallocatechin-3-gallate-stearate (EGCG-S), shows an increased stability and antibiofilm activity comparable to CHX (Melok et al., 2018). Moreover, the EGCG is less cytotoxic compared with CHX, and shows anti-inflammatory effects on S. mutans-stimulated odontoblast-like cells (Stavroullakis et al., 2021), indicating a good prospect in the management of oral infectious diseases. Propolis and its derivatives such as apigenin and trans-trans farnesol (tt-farnesol) have been identified to show a good antimicrobial activity against $S$. mutans and exhibit notable biological activities against dental caries for decades (Koo et al., 2002; Koo et al., 2003; Cardoso et al., 2010; Veloz et al., 2016). Apigenin has been shown to inhibit Gtfs, specifically GtfB and GtfC. tt-farnesol shows anti-caries effects by reducing cell viability and destabilizing oral biofilms rather than affecting Gtfs activities (Koo et al., 2002; Koo et al., 2005; Jeon et al., 2011). Caffeic acid phenethyl ester (CAPE), another extracted compound from propolis, shows broad-spectrum antimicrobial activity against various microbes including Enterococcus faecalis, S. aureus, Bacillus subtilis, Pseudomonas aeruginosa, etc (Velazquez et al., 2007). Niu et al. showed that CAPE affected the morphology of $S$. mutans biofilms, inhibited biofilm formation and maturation and reduced EPS production (Veloz et al., 2019; Niu et al., 2020). In addition, plenty of other natural compounds have also been identified exhibiting antibacterial effects against $S$. mutans. Piceatannol, a plant-derived stilbene, can target GtfC domain and inhibit glucans production, and thus reduces S. mutans biofilms formation (Nijampatnam et al., 2018). Piceatannol can also inhibit $\mathrm{F}_{1} \mathrm{~F}_{0}$-ATPase of $S$. mutans, and thus suppresses the aciduricity of $\mathrm{S}$. mutans (Sekiya et al., 2019). In addition, curcumin, a phytopolyphenols from traditional medicine known as turmeric, and its analog desmethoxycurcumin (DMC), also show inhibitory effect on $\mathrm{F}_{1} \mathrm{~F}_{0}$-ATPase of $S$. mutans and thus reduce its growth in acidic conditions (Sekiya et al., 2014; Nakanishi-Matsui et al., 2016; Sekiya et al., 2019). Ursolic acid, a plant-derived compound, shows inhibitory effects on EPS synthesis and biofilm formation of S. mutans (Kim et al., 2013; Lyu et al., 2021b). Astilbin, a flavanone compound from Rhizoma Smilacis Glabrae and $\beta$-sitosterol from kemangi, can inhibit SrtA activity and thus reduces the biofilm formation of S. mutans (Wang et al., 2019; Evangelina et al., 2021).

Small molecules designed for specific target is another approach to the inhibition of $S$. mutans. Charles et al. synthesized several peptides spanning residues 803-185 of antigen I/II, and identified a synthetic peptide p1025 that inhibited antigen I/II binding to salivary receptors by forming adhesion epitopes in a dosedependent way. The effect of p1025 against S. mutans was relatively stable, and it was able to selectively inhibit $S$. mutans recolonization to tooth surface (Kelly et al., 1999; Younson and Kelly, 2004; Li et al., 2009). Small molecules that show inhibitory effects on $S$. mutans are summarized in Table 1. 
TABLE 1 | Small molecules that inhibit S. mutans.

\begin{tabular}{|c|c|c|c|c|}
\hline Small molecules & Chemical structure & Mechanisms & $\begin{array}{l}\text { Antimicrobial } \\
\text { activity }\end{array}$ & Reference \\
\hline \multicolumn{5}{|l|}{ Drug-repositioning } \\
\hline LCG-N25 & & $\begin{array}{l}\text { Inhibit both the planktonic cells and } \\
\text { biofilms formation of } S \text {. mutans }\end{array}$ & $\mathrm{MIC}_{90}: 0.5 \mu \mathrm{g} / \mathrm{ml}$ & (Lyu et al., 2021a) \\
\hline \multicolumn{5}{|l|}{$\mathrm{MBC}_{90}: 15.6 \mu \mathrm{g} / \mathrm{ml}$} \\
\hline Napabucasin & & Inhibit S. mutans biofilms & $\begin{array}{l}\mathrm{MIC}_{90}: 3.91 \mu \mathrm{g} / \mathrm{ml} \\
\mathrm{MBC}_{90}: 15.63 \mu \mathrm{g} / \mathrm{ml} \\
\text { MBIC }_{90}: 1.95 \mu \mathrm{g} / \mathrm{ml} \\
\text { MBRC }_{90}: 62.5 \mu \mathrm{g} / \mathrm{ml}\end{array}$ & (Kuang et al., 2020) \\
\hline ZY354 & & $\begin{array}{l}\text { Inhibit S. mutans growth and } \\
\text { selectively inhibit the biofilm formation } \\
\text { of } S \text {. mutans }\end{array}$ & $\begin{array}{l}\text { MIC }_{90}: 0.24 \mu \mathrm{g} / \mathrm{ml} \\
\text { MBC }_{90}: 1.95 \mu \mathrm{g} / \mathrm{ml} \\
\text { MBIC }_{90}: 0.24 \mu \mathrm{g} / \mathrm{ml} \\
\text { MBRC }_{90}: 31.25 \mu \mathrm{g} / \\
\mathrm{ml}\end{array}$ & (Zhang et al., 2019) \\
\hline $11-6 s$ & & $\begin{array}{l}\text { Inhibit growth and exopolysaccharides } \\
\text { (EPS) generation of S. mutans; } \\
\text { inhibit the demineralization of tooth } \\
\text { enamel and induce no drug resistance } \\
\text { in S. mutans }\end{array}$ & $\begin{array}{l}\mathrm{MIC}_{90}: 3.91 \mu \mathrm{g} / \mathrm{ml} \\
\mathrm{MBC}_{90}: 15.63 \mu \mathrm{g} / \mathrm{ml} \\
\text { MBIC }_{90}: 3.91 \mu \mathrm{g} / \mathrm{ml} \\
\text { MBRC }_{90}: 62.5 \mu \mathrm{g} / \mathrm{ml}\end{array}$ & (Zhang J et al., 2021) \\
\hline \multicolumn{5}{|c|}{ Phenotypic screening from libraries } \\
\hline Compound 3F1 & & $\begin{array}{l}\text { Specifically disturb S. mutans biofilms } \\
\text { in a mixed biofilm }\end{array}$ & MDC: $5 \mu \mathrm{M}$ & (Garcia et al., 2017) \\
\hline D25 & & $\begin{array}{l}\text { Selectively inhibit S. mutans biofilms } \\
\text { without interfering planktonic cells }\end{array}$ & $\begin{array}{l}\text { Inhibit S. mutans } \\
\text { biofilms at the } \\
\text { concentration of } \\
3.125-25 \mu \mathrm{g} / \mathrm{mL}\end{array}$ & (Chen et al., 2021) \\
\hline G43 & & $\begin{array}{l}\text { Inhibit S. mutans biofilm formation by } \\
\text { selectively binding to GtfC }\end{array}$ & $\begin{array}{l}\text { Inhibit more than } \\
85 \% \text { of S. mutans } \\
\text { biofilms at } 12.5 \mu \mathrm{M}\end{array}$ & (Zhang et al., 2017) \\
\hline $\begin{array}{l}\text { Pyrimidinone or } \\
\text { pyrimidindione-fused 1,4- } \\
\text { naphthoquinones }\end{array}$ & & $\begin{array}{l}\text { Show bacteriostatic and bactericidal } \\
\text { effects against } \\
\text { S. mutans in both resistant and } \\
\text { sensitive strains }\end{array}$ & & (Kim K et al., 2020) \\
\hline $\begin{array}{l}\text { ZINC19835187 (ZI-187) } \\
\text { ZINC19924939 (ZI-939) }\end{array}$ & & $\begin{array}{l}\text { Inhibit S. mutans adhesion and biofilm } \\
\text { formation by targeting antigens } 1 / / \mid\end{array}$ & $\begin{array}{l}\text { Show no inhibitory } \\
\text { effects on } S \text {. mutans } \\
\text { growth at } 10-100- \\
1000 \mu \mathrm{M}\end{array}$ & (Rivera-Quiroga et al., 2020) \\
\hline ZINC 19924906 (ZI-906) & & & $\begin{array}{l}\text { Show inhibitory } \\
\text { effects on adhesion } \\
\text { than } 90 \% \text { at } 200 \mu \mathrm{M} \\
(\mathrm{Zl}-187 \text { at } 100 \mu \mathrm{M})\end{array}$ & \\
\hline 2A4 & & $\begin{array}{l}\text { Inhibit S. mutans adhesion and biofilm } \\
\text { formation by targeting antigens } 1 / \text { II and } \\
\text { glucosyltransferases (Gtfs) }\end{array}$ & $\begin{array}{l}\text { MIC50: } 2.0 \pm 0.5 \mu \mathrm{M} \\
\text { MBIC50: } 0.94 \pm 0.02 \\
\mu \mathrm{M} .\end{array}$ & (Liu et al., 2011) \\
\hline $\begin{array}{l}\text { 2-(4-methoxyphenyl)-N-(3- } \\
\{[2-(4-\text { methoxyphenyl)ethyl] } \\
\text { imino\}-1,4-dihydro-2- } \\
\text { quinoxalinylidene) } \\
\text { ethanamine }\end{array}$ & & $\begin{array}{l}\text { Inhibit the biofilm formation and } \\
\text { destroy mature biofilms without killing } \\
\text { S. mutans by inhibiting GtfC }\end{array}$ & $\begin{array}{l}\text { Reduce } 79 \% \text { S. } \\
\text { mutans biofilms cell } \\
\text { viable count at } 10 \\
\mu \mathrm{g} / \mathrm{ml}\end{array}$ & (Ren et al., 2016) \\
\hline
\end{tabular}


TABLE 1 | Continued

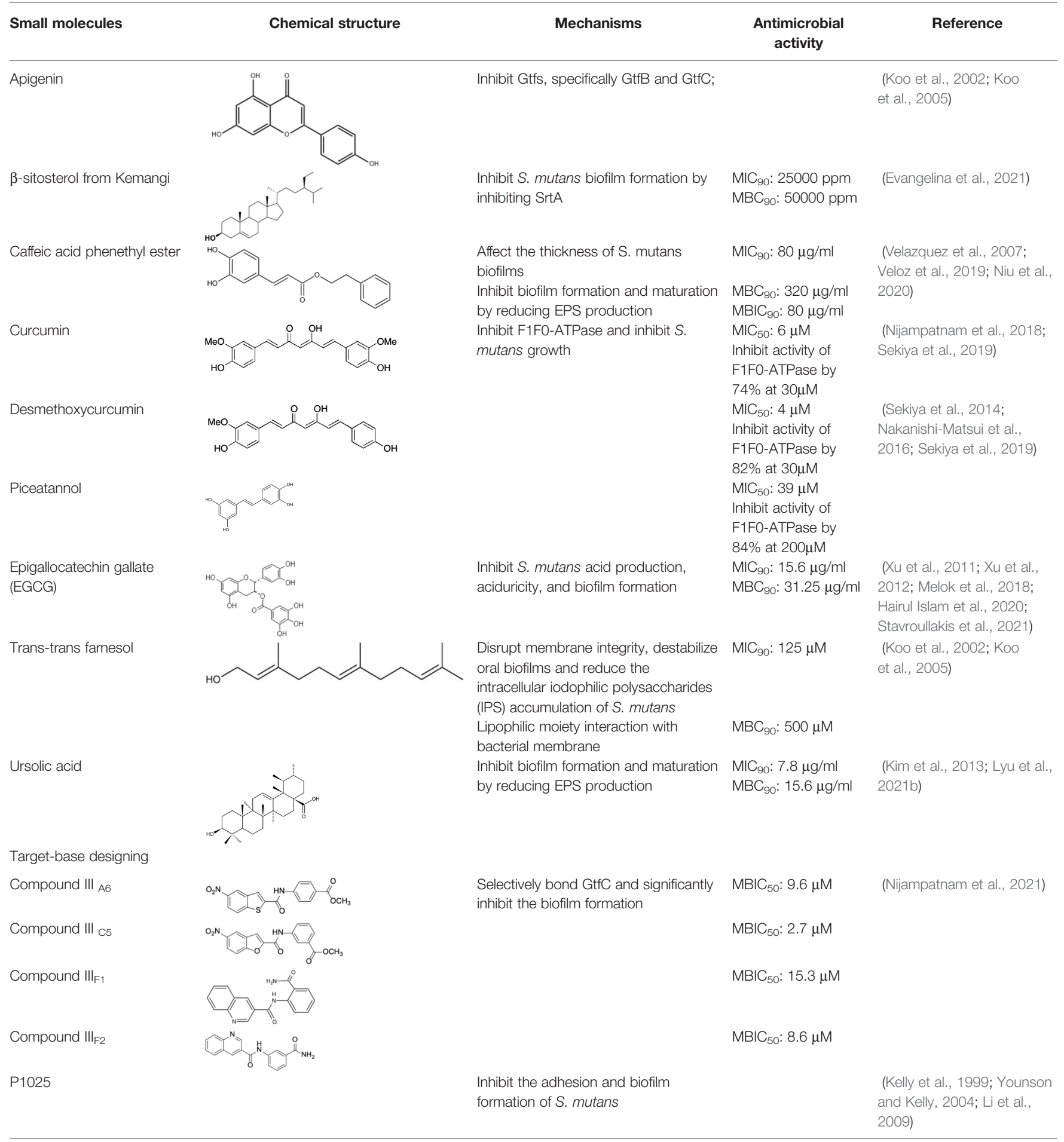

MIC, minimum inhibitory concentration; MBC, minimum bactericidal concentration; MBIC, minimum biofilm inhibition concentration; MBRC, minimum biofilm reduction concentration; $M D C$, concentration that a single dose of the small molecule needed to disperse $50 \%$ of the biofilm.

\section{Porphyromonas gingivalis}

$P$. gingivalis, despite its relatively low abundance in the periodontal microbiota, has been well recognized as the keystone species of periodontitis (Kojima et al., 1993). P. gingivalis expresses Argspecific cysteine proteinases (gingipains) that help the subversion of recruited leukocytes, leading to uncontrolled overgrowth of other proteolytic and asaccharolytic bacteria in the microbial biofilm, which in turn elevate the complement-dependent destructive inflammation of periodontal tissue and stabilize the transition of periodontal microbiota to a disease-provoking consortium 
(Hajishengallis et al., 2012; Hajishengallis, 2015). Specific inhibition of $P$. gingivalis could not only suppress its virulence to the periodontium, but also rescue the microbial dysbiosis induced by this keystone pathogen and ultimately shift the microbiota toward a community in favor of periodontal health (Hajishengallis et al., 2012).

The initial colonization of $P$. gingivalis in oral biofilms occurs in the supragingival biofilm (Wright et al., 2013). Adhesion of $P$. gingivalis to streptococci is critical for its pathogenicity. The minor fimbrial antigen (Mfa1) of $P$. gingivalis and streptococcal surface antigen I/II are involved in the interspecies adhension (Park et al., 2005; Daep et al., 2011). Roky identified 3 small molecules, namely N7, N17 and V8 from high-throughput screening of ZINC library, that inhibited $P$. gingivalis adherence to streptococci and reduced its virulence in vivo. In addition, compound N17 and V8 showed low cytotoxic activity in both human and marine cells (Roky et al., 2020). Another synthetic compound PCP-III-201, firstly designed as an inhibitor that mimics the natural peptide substrate recognized by Mfa, showed marked inhibition on the adherence of $P$. gingivalis to streptococci by interfering Mfa and antigenI/II interaction, and thus disrupted the formation of mixed biofilms (Tan et al., 2018). 1,2,3-triazole-based peptidomimetics, another natural peptide substrate simulants of Mfa, exhibited inhibitory effect on $P$. gingivalis adherence to oral streptococci by inhibiting the interaction of antigen I/II and Mfa proteins (Patil et al., 2016). Similarly, "the second generation" 1,2,3-triazole-based peptidomimetics based on the first-generation diphenyloxazole were designed and showed inhibitory effect on $P$. gingivalis adherence to $S$. gordonii, indicating the potential use of triazole derivatives in the management of periodontitis (Patil et al., 2019). The major fimbriae of $P$. gingivalis is another adhesin which can bind streptococcal surface component glyceraldehyde-3phosphate dehydrogenase (GAPDH) and mediates its adhesion to oral streptococci (Maeda et al., 2004; Daep et al., 2006). Three small molecules, namely 2A4, 2D11 and 2E11, which were screened from a library of small molecules based on the 2aminoimidazole and 2-aminobenzimidazole scaffolds, showed inhibitory effects on $P$. gingivalis by down-regulating Mfal and fimA gene expression, thus inhibiting the adherence of $P$. gingivalis to oral streptococci (Wright et al., 2014).

Natural extract is another abundant resource for inhibitors against $P$. gingivais (Abrao et al., 2021). Resveratrol, a natural compound with antimicrobial, antiviral and anticancer activities (Kolouchova et al., 2018), shows inhibitory effects on $P$. gingivalis. The minimum inhibitory concentrations (MIC) of resveratrol against $P$. gingivalis and other clinical strains are in the range of $78.12-156.25 \mu \mathrm{g} / \mathrm{ml}$. Besides, resveratrol can reduce the $P$. gingivalis biofilm formation and its virulence by downregulating the expression of fimbriae (type II and IV) and proteinases (kgp and rgpA) (Kugaji et al., 2019). A study evaluated a variety of natural products from medicinal plants and identified quite a few small molecular compounds that inhibited the growth and biofilm formation of $P$. gingivalis. Intriguingly, some of the derivatives also inhibited gingipains (Kariu et al., 2017). A natural polyphenol, Quercetin $\left(3,3^{\prime}, 4^{\prime}, 5,7-\right.$ pentahydroxyflavone), can inhibit gingipains activities and biofilm formation at sub-MIC concentrations. In addition, quercetin down-regulates the expression of virulence-associated genes of $P$. gingivalis ( $\mathrm{He}$ et al., 2020). Quantum curcumin, a derivative of curcumin, shows notable inhibitory effects on planktonic cells and biofilms of $P$. gingivalis, particularly via inhibition of gingipain R and K (Singh et al., 2019).

In addition, several other small molecules have also showed anti-inflammatory effects against periodontitis induced by $P$. gingivalis. Lei et al. synthesized a series of valproic acid pyrazole conjugates, and the most effective molecules $7 \mathrm{c}$ not only showed antibacterial effects against $P$. gingivalis, but also reduced inflammation by inhibiting TNF- $\alpha$, IL- $1 \beta$ and IL-6 (Dong et al., 2021). A sialidase inhibitor, 2-deoxy-2,3didehydro-N-acetylneuraminic acid (DANA), showed effects on reducing pathogenicity of $P$. gingivalis and exhibited antiinflammatory prospect (Yu et al., 2021). Small molecules that inhibit $P$. gingivalis are summarized in Table 2.

\section{Candida albicans}

C. albicans is an opportunistic pathogen in the oral cavity, which can cause oral fungal infections and increase the risk of oral epithelial carcinogenesis (Mayer et al., 2013). In addition, C. albicans robustly interacts with oral streptococci and can drive the microbial shift toward a more pathogenic microbiota that favors or aggravates the development of oral infectious diseases such as dental caries and periodontitis (Hajishengallis and Lamont, 2012).

Azoles, especially fluconazole (FLC) are the frontline treatment against fungal infections. However, with increasing drug resistance to current azole antifungals, small molecules have become a promising source for the development of novel antifungals (Kett et al., 2021). Azole antifungals inhibit sterol $14 \alpha$-demethylase (CYP51), resulting in synthesis disorder of ergosterol thereby affecting cell membrane integrity. Synthetic small molecules targeting CYP51 or inhibiting the synthesis of ergosterol are common strategies to inhibit C. albicans. Two kinds of small molecular azole derivatives (i.e. short and extended derivatives), have shown good binding affinity to CYP51, and thus potently inhibit CYP51 activity and the growth of C. albicans (Binjubair et al., 2020). Drug repurposing is also a promising approach to the identification of antifungals against C. albicans (Ashburn and Thor, 2004). A novel 1,2,4-triazole-indole hybrid molecule, (2(2,4-Dichlorophenyl)-3-(1H-indol-1-yl)-1-(1,2,4-1H-triazol-1-yl) propan-2-ol,namely $8 \mathrm{~g}$, showed a broad-spectrum activity against Candida with low cytotoxicity, probably due to its inhibitory effects on ergosterol synthesis and phospholipase A2-like activity (Pagniez et al., 2020). Monika et al. synthesized a series of benzoxazole derivatives showing equivalent effects to commercially used azoles, which either interacted with exogenous ergosterol or blocked the synthesis of endogenous ergosterol. Among the library of 23 benzoxazoles featuring 2mercaptobenzoxazole with the phenacyl moiety or respective alcohols, compound 5d showed good stability and water solubility, representing a good candidate in the treatment of andida infection (Staniszewska et al., 2021a). 
TABLE 2 | Small molecules that inhibit $P$. gingivalis.

\begin{tabular}{|c|c|c|c|c|}
\hline $\begin{array}{l}\text { Small } \\
\text { molecules }\end{array}$ & Chemical structure & Mechanisms & $\begin{array}{l}\text { Antimicrobial } \\
\text { activity }\end{array}$ & Reference \\
\hline \multicolumn{5}{|c|}{ Synthetic molecules } \\
\hline DANA & & $\begin{array}{l}\text { Inhibit growth and biofilm formation. Reduce expression of the fimA, fimR, and } \\
\text { fimS genes and decrease gingipains activity. Inhibit TNF- } \alpha, I L-1 \beta \text {, and iNOS } \\
\text { production in LPS-stimulated macrophages and prevent alveolar bone } \\
\text { absorption and inhibited TNF- } \alpha \text { and IL-1 } 1 \beta \text { production in vivo. }\end{array}$ & $\begin{array}{l}\text { Inhibit } P \text {. gingivalis } \\
\text { growth and biofilm } \\
\text { formation at } 1 \mathrm{mM}\end{array}$ & $\begin{array}{l}\text { (Yu et al., } \\
\text { 2021) }\end{array}$ \\
\hline N7 & & Inhibit $P$. gingivalis adherence to streptococci and reduced its virulence & & $\begin{array}{l}\text { (Roky } \\
\text { et al., } \\
\text { 2020) }\end{array}$ \\
\hline \multicolumn{5}{|l|}{ N17 } \\
\hline \multicolumn{5}{|l|}{ V8 } \\
\hline PCP-III-201 & & $\begin{array}{l}\text { Inhibit the adherence of } P \text {. gingivalis to streptococci by interfering Mfa and } \\
\text { antigenl/II interaction, and disrupt the formation of mixed biofilms }\end{array}$ & $\begin{array}{l}\text { Inhibit } 50 \% \text { the } \\
\text { incorporation of } P \text {. } \\
\text { gingivalis into the } \\
\text { three-species biofilm at } \\
15 \mu \mathrm{M} \\
\text { Inhibit preformed } \\
\text { three-species biofilm in } \\
\text { a dose-dependent } \\
\text { way. }\end{array}$ & $\begin{array}{l}\text { (Tan et al., } \\
\text { 2018) }\end{array}$ \\
\hline $\begin{array}{l}\text { 1,2,3-triazole- } \\
\text { based } \\
\text { peptidomimetics }\end{array}$ & & $\begin{array}{l}\text { Inhibit } P \text {. gingivalis adherence to } \mathrm{S} \text {. gordonii by inhibiting the interaction of } \\
\text { antigen } \mathrm{I} / \mathrm{II} \text { and Mfa proteins }\end{array}$ & & $\begin{array}{l}\text { (Patil } \\
\text { et al., } \\
\text { 2016; Patil } \\
\text { et al., } \\
\text { 2019) }\end{array}$ \\
\hline $2 \mathrm{~A} 4$ & & Inhibit $P$. gingivalis, and downregulate Mfa1 and fimA gene expression & $\mathrm{MIC}_{90}: 20 \mu \mathrm{M}$ & $\begin{array}{l}\text { (Wright } \\
\text { et al., } \\
\text { 2014) }\end{array}$ \\
\hline 2D11 & & & MIC50: $4.73 \mu \mathrm{M} \pm 1.77$ & \\
\hline 2E11 & & & MIC50: $6.88 \mu \mathrm{M} \pm 1.45$ & \\
\hline $7 \mathrm{C}$ & & $\begin{array}{l}\text { Inhibit microorganisms responsible for periodontitis including } P \text {. gingivalis, and } \\
\text { exhibit notable effects on reducing inflammation by inhibiting TNF- } \alpha, \mathrm{IL}-1 \beta \text { and } \\
\text { IL-6 }\end{array}$ & $\mathrm{MIC}_{90}: 0.05 \mu \mathrm{g} / \mathrm{ml}$ & $\begin{array}{l}\text { (Dong } \\
\text { et al., } \\
\text { 2021) }\end{array}$ \\
\hline \multicolumn{5}{|c|}{ Natural Compounds } \\
\hline Quercetin & & $\begin{array}{l}\text { Inhibit gingipains activities and biofilm formation, and down-regulate the } \\
\text { virulence-associated gene expressions of } P \text {. gingivalis }\end{array}$ & $\begin{array}{l}\mathrm{MIC}_{90}: 200 \mu \mathrm{M} \\
\mathrm{MBC}_{90}: 400 \mu \mathrm{M}\end{array}$ & $\begin{array}{l}(\mathrm{He} \text { et al., } \\
\text { 2020) }\end{array}$ \\
\hline $\begin{array}{l}\text { Quantum } \\
\text { curcumin }\end{array}$ & & $\begin{array}{l}\text { Inhibit planktonic cells and biofilms cells of } P \text {. gingivalis. In addition, inhibit } \\
\text { gingipains. }\end{array}$ & & $\begin{array}{l}\text { (Singh } \\
\text { et al., } \\
\text { 2019) }\end{array}$ \\
\hline Resveratrol & & $\begin{array}{l}\text { Inhibit the growth of } P \text {. gingivalis Reduce the } P \text {. gingivalis biofilm formation and } \\
\text { its virulence by downregulating the expression of fimbriae and proteinases }\end{array}$ & $\begin{array}{l}\mathrm{MIC}_{90}: 156.25 \mu \mathrm{g} / \mathrm{ml} \\
\mathrm{MBC}_{90}: 312.5 \mu \mathrm{g} / \mathrm{ml}\end{array}$ & $\begin{array}{l}\text { (Kugaji } \\
\text { et al., } \\
\text { 2019) }\end{array}$ \\
\hline
\end{tabular}

MIC, minimum inhibitory concentration; MBC, minimum bactericidal concentration; MBIC, minimum biofilm inhibition concentration; MBRC, minimum biofilm reduction concentration. 
C. albicans can form biofilms on the mucosal surface, which not only increase its virulence but also lead to drug resistance (Lohse et al., 2018). A study screened the Chembridge Small Molecule Diversity library containing 30,000 small molecules and identified 45 compounds which inhibited biofilm formation. Further investigation identified 4 compounds, namely CB06, CB14, CB36 and CB40, which inhibited biofilm formation and destroyed mature biofilm alone or in combination with other antifungals such as fluconazole and caspofungin (Lohse et al., 2020). Monika et al. screened 20 dibromobenzimidazole derivatives and identified a small molecule, namely 5h, which showed inhibitory effects on cell wall and reduced biofilm formation of Candida albicans. Besides, $5 \mathrm{~h}$ was identified as a mitochondrial inhibitor of both C. albicans and C. neoformans, indicating its potential in the anti-fungal treatment (Staniszewska et al., 2021b).

Morphological transformation between hyphae and yeast phase in C. albicans is also relevant to its virulence and drug resistance (Vediyappan et al., 2013). A recent study repurposed 18 non-antifungal agents including antipsychotics, antiarrhythmics, proton pump inhibitors (PPIs), and identified 7 drugs that inhibited C. albicans in a dose-dependent manner, among which, chlorpromazine (CHL) and prochlorperazine (PCP) were fungicidal and the other 5 fungistatic. In addition, 3 candidate compounds, including chlorpromazine, prochlorperazine and drotaverine, inhibited germ tube formation (Kathwate et al., 2021). A high-throughput in silico study screened 584 compounds and identified 5 candidate molecules, namely U73122, disulfiram, BSK805, BIX01294, and GSKJ4, among which disulfiram showed excellent antifungal effects and inhibited 50\% growth of C. albicans SC5314 strain at the concentration of $1 \mathrm{mg} / \mathrm{ml}$. Disulfiram also inhibited $50 \%$ growth of C. albicans biofilms at a concentration ranging from $32-128 \mathrm{mg} /$ $\mathrm{ml}$ (Hao et al., 2021). A series of non-peptidic analogues of the broad-spectrum host defense peptides (HDPs) have also shown antifungal activities (Ryan et al., 2014). A compound 4 (C4) screened form HDP-mimic compound library can kill both the yeast and hyphal form of $C$. albicans at a concentration of $8 \mu \mathrm{g} / \mathrm{ml}$ (Menzel et al., 2017), suggesting a potential use in the control of invasive candidiasis.

C. albicans has several adhesins such as glutenin-like sequence (Als) family (Als1-Als7 and Als9), which mediate its adhesion to the host surface (Hoyer, 2001). Among Als family, the protein Als3 plays an important role in adhesion and hypha formation (Murciano et al., 2012). A small molecule, F2768-0318, shows inhibitory effects on the virulence factors related to adhesion and biofilm formation by inhibiting Als3 protein (Shinobu-Mesquita et al., 2020). Besides, machineries that modulate the stress responses are linked to fungal resistance. Heat shock protein 90 (Hsp90), an essential molecule in the stress responses of eukaryotes is also involved in the morphological transformation and drug resistance of C. albicans (Cowen and Lindquist, 2005; Taddei et al., 2014; Tiwari et al., 2015; Whitesell et al., 2019), and thus represents a promising target for the development of small molecules against Candidal infection. Yuan et al. screened 4 hsp90 inhibitors and identified a most potential compound, namely ganetspib, which exhibited significant synergistic activity with fluconazole in both planktonic cells and biofilms. The ganetspib in combination with FLC also down-regulated the expression of azole-targeting enzyme ERG11 and efflux pump CDR1, CDR2, and MDR1. The synergistic effects of ganetspib with FLC in vivo also indicating its potential use as an antifungal enhancer of azoles in Candida infections (Yuan et al., 2021).

The over-expressed drug efflux pump on the cell membrane is another common virulence trait of $C$. albicans being related to azole resistance. Development of compounds that inhibit efflux pump and increase the concentration of drugs in the cell is a classic strategy to increase fluconazole sensitivity (Coste et al., 2004; Holmes et al., 2016). Kali et al. screened 2454 small molecules against C. auris and identified a bisbenzodioxolylindolinone CMLD012336, a 3,3-diarylated oxindole (also called azoffluxin), which showed synergistic interaction with fluconazole against a resistant strain of $C$. auris. Mechanistically, azoffluxin increased fluconazole sensitivity in both $C$. auris and C. albicans by inhibiting efflux pump CDR1 (Iyer et al., 2020). Another compound screened from a series of synthesized cyclobutene-dione (squarile) small molecules library, namely compound A, also showed inhibitory effect on MFS efflux pump CaMdrlp, and thus sensitized AD/ CaMDR1 to FLC (Keniya et al., 2015). In addition, a small molecule ENOblock showed good inhibitory effects alone and in combination with FLC against C. albicans hypha and biofilm formation in vivo. Mechanistically, ENOblock interacted with $\mathrm{CaEnol}$ and significantly inhibited the transglutaminase activity of CaEno1, and thus affected the growth and morphogenesis of C. albicans (Li et al., 2019). Small molecules that show inhibitory effects against C. albicans are summarized in Table 3.

\section{SMALL MOLECULES THAT INHIBIT QUORUM SENSING SYSTEM}

Different microorganisms exist in oral microbiota, and the robust microbial interactions have close relationship with host health and diseases. Small molecules which disrupt microorganism interactions may rescue the microbial disequilibrium, contributing to the management of oral infectious diseases. Quorum sensing (QS) system, a mechanism of microbial interaction, involves signaling molecules that enable a cell to sense cell density (Padder et al., 2018). It relies on the production, release and recognition of self-induced signal molecules and regulates various biological behaviors including biofilm formation, microbial virulence and resistance (Papenfort and Bassler, 2016). Small signal molecules concentrated in the extracellular environment mediate QS in fungi. The mechanisms accountable for the accumulation of these molecules include passive diffusion, efflux pumps and specific transporters (Padder et al., 2018).

ComA is a critical component of S. mutans QS system (Havarstein et al., 1995). Ishii et al. found a compound that inhibited the peptidase domain (PEP) of ComA, thus disrupting the QS system and inhibiting biofilm formation of S. mutans. This compound also inhibited the PEP of Streptococcus 
TABLE 3 | Small molecules that inhibit C. albicans.

$\begin{array}{ll}\begin{array}{l}\text { Small } \\ \text { molecules }\end{array} & \begin{array}{l}\text { Chemical } \\ \text { structure }\end{array} \\ \text { Drug-repositioning } & \begin{array}{l}\text { Show broad-spectrum activity against Candida with low cytotoxicity due } \\ \text { to its inhibitory effects on ergosterol synthesis and phospholipase A2- } \\ \text { like activity }\end{array}\end{array}$

Antimicrobial activity

Reference

Phenotypic screening from molecule libraries

\begin{tabular}{|c|c|c|c|}
\hline azoffluxin & $\begin{array}{l}\text { Increase fluconazole sensitivity in both } C \text {. auris and C. albicans by } \\
\text { inhibiting efflux pump CDR1 }\end{array}$ & & $\begin{array}{l}\text { (lyer et al., } \\
\text { 2020) }\end{array}$ \\
\hline $\begin{array}{l}\text { Compound } \\
\text { A }\end{array}$ & Inhibit MFS efflux pump CaMdr1p & $\mathrm{FlCl}<0.05$ & $\begin{array}{l}\text { (Keniya et al., } \\
\text { 2015) }\end{array}$ \\
\hline CB06 & $\begin{array}{l}\text { Inhibit biofilm formation and destroy mature biofilm in combination with } \\
\text { other antifungals }\end{array}$ & $\begin{array}{l}\text { Inhibit biofilm formation in the } \\
\text { presence of FLC at } 12.5 \mu \mathrm{M}\end{array}$ & $\begin{array}{l}\text { (Lohse et al., } \\
\text { 2020) }\end{array}$ \\
\hline CB14 & & $\begin{array}{l}\text { Destroy mature biofilm in the } \\
\text { presence of caspofungi at } \\
12.5 \mu \mathrm{M}\end{array}$ & \\
\hline CB36 & & $\begin{array}{l}\text { Inhibit biofilm formation and } \\
\text { destroy mature biofilm in the } \\
\text { presence of caspofungi at } \\
12.5 \mu \mathrm{M}\end{array}$ & \\
\hline CB40 & & $\begin{array}{l}\text { Destroy mature biofilm in the } \\
\text { presence of caspofungi at } \\
12.5 \mu \mathrm{M}\end{array}$ & \\
\hline C4 & Kill both the yeast and hyphal form of $C$. albicans & $\begin{array}{l}\mathrm{MIC}_{90}: 2 \mu \mathrm{g} / \mathrm{ml} \\
\mathrm{MFC}_{90}: 8 \mu \mathrm{g} / \mathrm{ml}\end{array}$ & $\begin{array}{l}\text { (Menzel et al., } \\
\text { 2017) }\end{array}$ \\
\hline Disulfiram & Inhibit C. albicans planktonic cells and biofilms & $\begin{array}{l}\mathrm{MIC}_{50}: 1 \mathrm{mg} / \mathrm{ml} \\
\mathrm{SMIC}_{50}: 32-128 \mathrm{mg} / \mathrm{ml}\end{array}$ & $\begin{array}{l}\text { (Hao et al., } \\
2021)\end{array}$ \\
\hline ENOblock & $\begin{array}{l}\text { Show effects alone or in combination with FLC against C. albicans } \\
\text { hypha and biofilm formation in vivo. } \\
\text { Interact with CaEno1 and inhibit the transglutaminase activity of CaEno1 } \\
\text { in C. albicans }\end{array}$ & $\begin{array}{l}\mathrm{MlC}_{90}: 32 \mu \mathrm{g} / \mathrm{ml} \\
\mathrm{FICl}<0.5 \text { (C.albicans 0304103) }\end{array}$ & $\begin{array}{l}(\text { Li et al., } \\
\text { 2019) }\end{array}$ \\
\hline $\begin{array}{l}\text { F2768- } \\
0318\end{array}$ & $\begin{array}{l}\text { Inhibit virulence factors related to adhesion and biofilm formation by } \\
\text { inhibiting Als3 protein }\end{array}$ & $\begin{array}{l}\mathrm{MIC}_{90}: 256 \mu \mathrm{g} / \mathrm{ml} \\
\mathrm{MFC}_{90}: 256 \mu \mathrm{g} / \mathrm{ml}\end{array}$ & $\begin{array}{l}\text { (Shinobu- } \\
\text { Mesquita } \\
\text { et al., 2020) }\end{array}$ \\
\hline Ganetespib & $\begin{array}{l}\text { Show synergistic activity with fluconazole in both planktonic cells and } \\
\text { biofilms, and down-regulate the expression of azole-targeting enzyme } \\
\text { gene ERG11 and efflux pump genes CDR1, CDR2, and MDR1 }\end{array}$ & $\mathrm{FICl}<0.05$ & $\begin{array}{l}\text { (Yuan et al., } \\
\text { 2021) }\end{array}$ \\
\hline $5 h$ & $\begin{array}{l}\text { Inhibit cell wall and inhibit biofilm formation. } \\
\text { Inhibit mitochondrion in both C. albicans ref and C. neoformans }\end{array}$ & $\mathrm{MlC}_{50}: 8 \mu \mathrm{g} / \mathrm{ml}$ & $\begin{array}{l}\text { (Staniszewska } \\
\text { et al., 2021b) }\end{array}$ \\
\hline
\end{tabular}

MIC, minimum inhibitory concentrations; MFC, minimum fungicidal concentrations; sMIC, sessile minimum inhibitory concentrations; FICl, fractional inhibitory concentration index. 
pneumoniae and Streptococcus. oralis (Ishii et al., 2017). Kaur et al. synthesized a compound called 1,3-disubstituted urea derivatives, which inhibited the activity of ComA by binding to the active sites of PEP. 1,3-disubstituted urea derivatives was able to inhibit the formation of $S$. mutans biofilm alone or in combination with low concentration fluoride (Kaur et al., 2016). DMTU (1,3-di-m-tolyl-urea) is an aromatic compound showing antibiofilm effects against Streptococcus mutans by inhibiting its quorum sensing pathway (comDE) (Kaur et al., 2017). In addition, DMTU significantly inhibited the formation of multispecies biofilms consisting of Streptococcus gordonii, Fusobacterium nucleatum, Porphyromonas gingivalis and Aggregatibacter actinomycetemcomitans at $12.5 \mu \mathrm{M}$ without affecting cell viability. DMTU also down-regulated the expression of virulence genes in $P$. gingivalis such as $\mathrm{mfa} 1$, rgpA and rgpB (Kalimuthu et al., 2020).

Autoinducier-2 (AI-2) is anthor QS molecule that is produced and recognized by $S$. mutans, S. gordonii, $P$. gingivalis and Fusobacterium nucleatum (Shao and Demuth, 2010). Park et al. (Park JS et al., 2017) found that 3-(dibromomethylene) isobenzofuran-1 $(3 \mathrm{H})$-one derivatives inhibited the activity of AI2 in F. nucleatum and reduced its biofilm formation. Another study found that D-galactose not only inhibited AI-2 activity, but also dose-dependently inhibited the biofilm formation of $F$. nucleatum, P. gingivalis, and T. forsythia (Ryu et al., 2016).

\section{NOVEL DRUG DELIVERY SYSTEMS OF ANTIMICROBIAL SMALL MOLECULES}

Drug delivery system (DDS) is an advanced means that improves the therapeutic characteristics of conventional drugs over the last few decades. Various pharmacological properties of drugs, such as pharmacokinetics and biodistribution can be altered by using small-scale DDS such as nanoparticles (NP) and microparticles. Currently, nanotechnology has been extensively explored in DDS concerning the antimicrobial properties of drugs. The incorporation of drugs into nanoparticles and nanocomposites by physical encapsulation, adsorption, or chemical conjugation, can notably enhance the pharmacokinetics and therapeutic efficacy of the drugs in the treatment of infectious diseases as compared to their free counterparts (Zhang et al., 2010). In recent years, nano-based delivery system containing small molecular antimicrobials, either derived from natural or synthetic compounds, has attracted increasing attentions in the field of oral microbial infection control. Nowadays, since antimicrobial resistance (AMR) has been arousing global concerns in the clinical practice, a variety of innovative nanotechnologies have been applied to improve the therapeutic properties of small molecules. Antimicrobial small molecules can be conjugated with or encapsulated into various nanoparticles including organic polymers and metallic nanoparticles (MNPs), exhibiting elevated solubility (Yang et al., 2009; Nicolosi et al., 2015), biocompatibility (Wang et al., 2020) and controlled release (Barman et al., 2014), and thus benefit the control of oral infectious diseases.

\section{Organic Polymers \\ Polysaccharides}

Polysaccharides are notable for targeted drug delivery systems as natural biomaterials. Polysaccharides are inexpensive and possess promising biocompatibility and biodegradability. In the polysaccharides-based drug delivery system, the loaded agents can be absorbed into external compartments or limited within the external surface, which can augment the stability and aqueous solubility of drugs (Barclay et al., 2019). Maghsoudi et al. compared the anticariogenic activities of three curcuminloaded polysaccharide nanoparticles including starch, alginate and chitosan. The results showed that polysaccharide nanoparticles possessed enhanced antimicrobial activities as compared to pure curcumin. Among the three curcuminloaded polysaccharide nanoparticles, the chitosan nanoparticles showed the largest amount of release and the best anticariogenic properties particularly at lower pH (Maghsoudi et al., 2017). Jahanizadeh et al. incorporated carboxymethyl starch (CMS), a modified starch with unique negatively charged groups with chitosan to develop a novel curcumin-loaded nanocomposite. This nanocomposite showed enhanced antimicrobial and antibiofilm properties against $S$. mutans. Meanwhile, this nanocomposite had a smaller nanoscale with an average size of $35.9 \mathrm{~nm}$ and exhibited excellent curcumin entrapment efficiency of $91 \%$ (Jahanizadeh et al., 2017).

\section{Poly Lactic-Co-Glycolic Acid Copolymer}

Poly lactic-co-glycolic acid (PLGA) is a synthetic polymer extensively utilized in the field of drug delivery system due to its biocompatible, biodegradable and sustained-release characteristics (Kapoor et al., 2015). Numerous PLGA-based drug delivery systems have been designed with different hydrophilic moieties such as poly ethylene glycol (PEG) or poly ethylene oxide (PEO) to increase the solubility of small molecules (Mir et al., 2017). Gürsu et al. synthesized farnesolloaded PLGA nanoparticles to enhance the bioavailability of farnesol. PLGA chemically interacted with the $\mathrm{OH}$ group of farnesols, and $22.5 \%$ of the equivalent amounts of nanoparticles achieved a similar inhibitory effect against C. albicans (Gürsu, 2020). Ahmadi et al. modified a photoexcited orthodontic adhesive by incorporating curcumin-loaded PLGA nanoparticles and explored its anti-biofilm effects against $S$. mutans, shear bond strength (SBS) and adhesive remnant index (ARI). The results showed that the antimicrobial activity of the blue laser-7\% wt. Curcumin-PLGA nanoparticles was comparable to $2 \%$ chlorhexidine. Moreover, the modified adhesive showed the highest SBS value and comparable ARI relative to the original pure adhesive (Ahmadi et al., 2020).

\section{Liposome}

Liposome owns many critical clinical features, especially excellent biocompatibility and capability of encapsulating both hydrophilic and hydrophobic compounds (Samad et al., 2007). The most attractive feature of liposome delivery systems is enhancing pharmacokinetic properties and bactericidal activities of the new or existing drugs as well as reducing their 
drugs' adverse effects (Alhariri et al., 2013). Nicolosi et al. reported that fusidic acid-loaded fusogenic liposomes increased the antimicrobial activities and broadened the antimicrobial spectrum in contrast to free drugs. The fusogenic small unilamellar vesicles may elevate the penetration of lipophilic drug into microorganisms and thus improve its antimicrobial properties (Nicolosi et al., 2015). However, the nanocarrier without being activated by specific stimuli cannot specifically reach and work in the targeting sites in vivo. Controlled drug release is promising for the trigger-release of liposomes in the clinical applications (Bibi et al., 2012). Mizukami et al. developed two enzyme-activity-triggered drug release systems by combining an antimicrobial peptide temporin L (TL) with surface-anionic liposomes. Protease and phosphatase were chosen as the target enzymes. For the protease-triggered system, a branched peptide that suppressed membranedamaging activity was fabricated by modifying the cationic Lys residue of TL. As for the phosphatase-triggered system, a neutral amino acid with an anionic phosphorylated amino acid in the lipophilic region of TL was replaced. The phosphopeptides alleviated its membrane-damaging activity so that controlled release was achieved (Mizukami et al., 2017).

\section{Metallic Nanoparticles}

Metallic nanoparticles can efficiently cope with resistant microbial strains due to its potential antimicrobial activity (Rai et al., 2017). A vast number of studies have demonstrated that silver nanoparticles have strong antimicrobial activities against various microorganisms including resistant pathogens (Rai et al., 2017). However, the toxicity of silver and many other metallic nanoparticles limits their clinical application (Mizukami et al., 2017). Yin et al. developed silver nanoparticles containing EGCG as reducing agent, which showed elevated biocompatibility than silver nitrate (AgNO3). Moreover, it also exhibited much lower MIC and MBC against $S$. mutans and potently inhibited acid and polysaccharide production (Yin et al., 2019). In contrast to other NPs, gold NPs (Au NPs) have many advantages, including controllable synthesis, versatility in surface modification, and admirable biocompatibility (Zhao et al., 2013; Yang et al., 2017). Although gold NPs usually show weak inherent antimicrobial activities (Rai et al., 2017), they can be modified or coated on different surfaces to function with antimicrobial properties. Wang, et al. synthesized a series of $\mathrm{N}$-heterocyclic moleculecoated gold NPs, among which 2-mercaptoimidazole (MI)- and 3-amino-1,2,4-triazole-5- thiol (ATT)-capped Au NPs showed broad-spectrum antibiofilm activities against MDR bacteria, including MRSA and MDR Escherichia coli (MDR E. coli). These NPs directly contacted and disrupted the cell wall of microorganisms, thus less likely to induce antimicrobial resistance. Moreover, taking into account the advantages of ultrasound-assisted coating method being highly durable and able to withstand a large number of washing cycles, Wang et al. used sonochemistry to coat Au NPs on the surface of fabrics, which showed excellent antimicrobial activity (Wang et al., 2020). S. Jabir et al. also reported that a linalool loaded on glutathione-modified gold nanoparticles in spherical shape was antimicrobial against gram-positive bacteria representing a biocompatible and less complicated and time-consuming approach to the delivery of antimicrobial small molecules (Jabir et al., 2018). Lu et al. developed a small molecule 2mercapto-1-methylimidazole-capped Chitosan-functionalized nanocomposites whose cationic amine rendered transport of the nanocomposites towards the negatively charged bacterial cell surface. With the alliance between small Imidazol molecules and gold nanoparticles, the nanocomposites exhibited bactericidal and biofilm disruption effects against both Gramnegative E. coli and Gram-positive S. aureus. Besides, these nanocomposites can be easily synthesized with low toxicity, showing good potential in clinical applications (Jabir et al., 2018). Apart from incorporating with inherent antimicrobial small molecules, Zhao et al. incorporated a non-antimicrobial molecule 4,6-diamino-2-pyrimidinethiol (DAPT) with Au-NPs. The DAPT-decorated Au-NPs was able to inhibit most of MDR Gram-negative bacteria such as E. coli and MDR Pseudomonas aeruginosa by suppressing energy metabolism and damaging bacterial membrane (Zhao et al., 2010).

\section{Tetrahedral Framework Nucleic Acids}

In recent years, tetrahedral framework nucleic acids (tFNAs) have attracted increasing attention due to their editability and biocompatibility (Zhang et al., 2020). Drug delivery based tFNAs has been proposed and investigated broadly over the past years (Li et al., 2021; Zhang et al., 2022). Zhang et al. synthesized tFNA/His-5, and by the modification of tFNAs, His-5 showed increased transport efficiency and improved anti-fungal effect (Zhang B et al., 2021). Moreover, Zhang et al. also developed tFNAs with a controllable conformation as a delivery vehicle for antisense oligonucleotides, which provided a better platform for the applications of antisense antibacterial therapeutics (Zhang et al., 2018). Besides, Sun et al. found tFNAs-ampicillin had a better antimicrobial effect and lower levels of drug resistance development than free ampicillin (Sun et al., 2020). However, it is doubtful that tFNAs could carry some molecules that are beyond their size and weight. Besides, attaching nucleic acids with complex secondary structures may inhibit the uptake process. Wider potential to deliver different cargos still need to be explored (Zhang et al., 2020).

\section{Virus-Derived Nanoparticles}

Although metallic nanoparticles have been explored as nanocarriers for small molecular antimicrobials, its accumulation within human body and interactions with organs and microenvironment have aroused concerns for its potential toxicity. Metallic nanoparticles can also stimulate the expression of cytokines that generate cytotoxicity, immunotoxicity, and genotoxicity (Zazo et al., 2017). To avoid these side effects, organic nanoparticles have attracted increasing attentions. Currently, virus-derived nanoparticles (VNPs), a self-assemblycompetent protein have shown advantages such as biodegradable, cost-effective and highly modifiable (Verma et al., 2018). Velázquez-Lam et al. conjugated EGCG to turnip mosaic virus (TuMV) particles, and the EGCG-TuMV VNPs not only maintained TuMV structure but also exhibited elevated antimicrobial and antibiofilm activities compared with free 
EGCG. Moreover, EGCG-VNP showed a high stability after six months of being stored at $4^{\circ} \mathrm{C}$. Of note, the various modifiable sites of VNPs provide the versatility for novel nanocarriers in drug delivery system (Velaäzquez-Lam et al., 2020).

\section{CONCLUSION}

Oral microbial dysbiosis is the most essential causative factor for common oral infectious diseases including dental caries and periodontal diseases. Small molecules with potent antimicrobial activity, high selectivity, and low toxicity are promising for the ecological management of oral diseases. Many small molecules have already been repurposed, screened and designed. However, many issues have yet to be solved. Although antimicrobial activities have been revealed for many small molecules, their mode of action and underlying mechanism are still unclear. The exact targets of some novel small molecules have yet to be identified. Therefore, structural modifications and optimization based on the candidates with confirmed mechanism and targets are promising. In addition, although the antimicrobial activity of small molecules against the keystone pathogens such as $S$. mutans and $P$. gingivalis has been demonstrated, their

\section{REFERENCES}

Abrao, F., Silva, T. S., Moura, C. L., Ambrosio, S. R., Veneziani, R. C. S., de Paiva, R. E. F., et al. (2021). Oleoresins and Naturally Occurring Compounds of Copaifera Genus as Antibacterial and Antivirulence Agents Against Periodontal Pathogens. Sci. Rep. 11 (1), 4953. doi: 10.1038/s41598-02184480-7

Ahmadi, H., Haddadi-Asl, V., Ghafari, H.-A., Ghorbanzadeh, R., Mazlum, Y., and Bahador, A. (2020). Shear Bond Strength, Adhesive Remnant Index, and AntiBiofilm Effects of a Photoexcited Modified Orthodontic Adhesive Containing Curcumin Doped Poly Lactic-Co-Glycolic Acid Nanoparticles: An Ex-Vivo Biofilm Model of S. Mutans on the Enamel Slab Bonded Brackets. Photodiagnosis Photodyn. Ther. 30, 101674. doi: 10.1016/j.pdpdt.2020.101674

Alhariri, M., Azghani, A., and Omri, A. (2013). Liposomal Antibiotics for the Treatment of Infectious Diseases. Expert Opin. Drug Deliv. 10 (11), 1515-1532. doi: $10.1517 / 17425247.2013 .822860$

Ang, C. W., Jarrad, A. M., Cooper, M. A., and Blaskovich, M. A. T. (2017). Nitroimidazoles: Molecular Fireworks That Combat a Broad Spectrum of Infectious Diseases. J. Med. Chem. 60 (18), 7636-7657. doi: 10.1021/ acs.jmedchem.7b00143

Ashburn, T. T., and Thor, K. B. (2004). Drug Repositioning: Identifying and Developing New Uses for Existing Drugs. Nat. Rev. Drug Discov. 3 (8), $673-$ 683. doi: $10.1038 / \mathrm{nrd} 1468$

Banas, J. A. (2004). Virulence Properties of Streptococcus Mutans. Front. Biosci. 9, 1267-1277. doi: 10.2741/1305

Barclay, T. G., Day, C. M., Petrovsky, N., and Garg, S. (2019). Review of Polysaccharide Particle-Based Functional Drug Delivery. Carbohydr. Polym. 221, 94-112. doi: 10.1016/j.carbpol.2019.05.067

Barman, S., Mukhopadhyay, S. K., Behara, K. K., Dey, S., and Singh, N. P. (2014). 1-Acetylpyrene-Salicylic Acid: Photoresponsive Fluorescent Organic Nanoparticles for the Regulated Release of a Natural Antimicrobial Compound, Salicylic Acid. ACS Appl. Mater. Interfaces 6 (10), 7045-7054. doi: 10.1021/am500965n

Besingi, R. N., Wenderska, I. B., Senadheera, D. B., Cvitkovitch, D. G., Long, J. R., Wen, Z. T., et al. (2017). Functional Amyloids in Streptococcus Mutans, Their Use as Targets of Biofilm Inhibition and Initial Characterization of SMU_63c. Microbiol. (Read.) 163 (4), 488-501. doi: 10.1099/mic.0.000443 ecological impact on the disease-provoking microbiota still needs further investigation in a more sophisticated microbial consortium and validation in vivo. Small molecules that disrupt microbial interactions without necessarily killing the bacteria is also promising, particularly in the light of robust advancement in the development of drug delivery system that enhances its substantivity and specificity. Finally, comprehensive evaluation of the long-term cytotoxicity in vivo is still needed to better translate those promising candidates to the clinical application.

\section{AUTHOR CONTRIBUTIONS}

RY and XX conceived and designed the review. SY, XL, JZ, and YS wrote the first draft of the manuscript. RY and XX helped revise the manuscript. All authors contributed to the article and approved the submitted version.

\section{FUNDING}

This study was supported by the National Natural Science Foundation of China (81771099, 81800989).
Bibi, S., Lattmann, E., Mohammed, A. R., and Perrie, Y. (2012). Trigger Release Liposome Systems: Local and Remote Controlled Delivery? J. Microencapsul. 29 (3), 262-276. doi: 10.3109/02652048.2011.646330

Binjubair, F. A., Parker, J. E., Warrilow, A. G., Puri, K., Braidley, P. J., Tatar, E., et al. (2020). Small-Molecule Inhibitors Targeting Sterol 14alpha-Demethylase (CYP51): Synthesis, Molecular Modelling and Evaluation Against Candida Albicans. ChemMedChem. 15 (14), 1294-1309. doi: 10.1002/cmdc.202000250

Bowen, W. H., Burne, R. A., Wu, H., and Koo, H. (2018). Oral Biofilms: Pathogens, Matrix, and Polymicrobial Interactions in Microenvironments. Trends Microbiol. 26 (3), 229-242. doi: 10.1016/j.tim.2017.09.008

Bowen, W. H., and Koo, H. (2011). Biology of Streptococcus Mutans-Derived Glucosyltransferases: Role in Extracellular Matrix Formation of Cariogenic Biofilms. Caries Res. 45 (1), 69-86. doi: 10.1159/000324598

Bramstedt, F. (1968). [Polysaccharide Synthesis Through Plaque Streptococci as an Important Factor in the Etiology of Caries]. DDZ 22 (11), 563-4 passim.

Cardoso, R. L., Maboni, F., Machado, G., Alves, S. H., and de Vargas, A. C. (2010). Antimicrobial Activity of Propolis Extract Against Staphylococcus Coagulase Positive and Malassezia Pachydermatis of Canine Otitis. Vet. Microbiol. 142 (34), 432-434. doi: 10.1016/j.vetmic.2009.09.070

Chen, Y., Ju, Y., Li, C., Yang, T., Deng, Y., and Luo, Y. (2019). Design, Synthesis, and Antibacterial Evaluation of Novel Derivatives of NPS-2143 for the Treatment of Methicillin-Resistant S. Aureus (MRSA) Infection. J. Antibiot. (Tokyo) 72 (7), 545-554. doi: 10.1038/s41429-019-0177-9

Chen, X., Liu, C., Peng, X., He, Y., Liu, H., Song, Y., et al. (2019). Sortase A-Mediated Modification of the Streptococcus Mutans Transcriptome and Virulence Traits. Mol. Oral. Microbiol. 34 (5), 219-233. doi: 10.1111/omi.12266

Chen, Y., Cui, G., Cui, Y., Chen, D., and Lin, H. (2021). Small Molecule Targeting Amyloid Fibrils Inhibits Streptococcus Mutans Biofilm Formation. AMB Express 11 (1), 171. doi: 10.1186/s13568-021-01333-2

Coste, A. T., Karababa, M., Ischer, F., Bille, J., and Sanglard, D. (2004). TAC1, Transcriptional Activator of CDR Genes, Is a New Transcription Factor Involved in the Regulation of Candida Albicans ABC Transporters CDR1 and CDR2. Eukaryot. Cell 3 (6), 1639-1652. doi: 10.1128/EC.3.6.16391652.2004

Cowen, L. E., and Lindquist, S. (2005). Hsp90 Potentiates the Rapid Evolution of New Traits: Drug Resistance in Diverse Fungi. Science 309 (5744), 2185-2189. doi: $10.1126 /$ science. 1118370 
Daep, C. A., James, D. M., Lamont, R. J., and Demuth, D. R. (2006). Structural Characterization of Peptide-Mediated Inhibition of Porphyromonas Gingivalis Biofilm Formation. Infect. Immun. 74 (10), 5756-5762. doi: 10.1128/ IAI.00813-06

Daep, C. A., Novak, E. A., Lamont, R. J., and Demuth, D. R. (2011). Structural Dissection and In Vivo Effectiveness of a Peptide Inhibitor of Porphyromonas Gingivalis Adherence to Streptococcus Gordonii. Infect. Immun. 79 (1), 67-74. doi: 10.1128/IAI.00361-10

Davison, E. K., and Brimble, M. A. (2019). Natural Product Derived Privileged Scaffolds in Drug Discovery. Curr. Opin. Chem. Biol. 52, 1-8. doi: 10.1016/ j.cbpa.2018.12.007

Dewhirst, F. E., Chen, T., Izard, J., Paster, B. J., Tanner, A. C., Yu, W. H., et al. (2010). The Human Oral Microbiome. J. Bacteriol. 192 (19), 5002-5017. doi: 10.1128/JB.00542-10

Dong, L., Fang, L., Dai, X., Zhang, J., Wang, J., and Xu, P. (2021). Antibacterial and Anti-Inflammatory Activity of Valproic Acid-Pyrazole Conjugates as a Potential Agent Against Periodontitis. Drug Dev. Res. doi: 10.1002/ ddr. 21851

Evangelina, I. A., Herdiyati, Y., Laviana, A., Rikmasari, R., Zubaedah, C., Anisah,, et al. (2021). Bio-Mechanism Inhibitory Prediction of Beta-Sitosterol From Kemangi (Ocimum Basilicum L.) as an Inhibitor of MurA Enzyme of Oral Bacteria: In Vitro and In Silico Study. Adv. Appl. Bioinform. Chem. 14, 103-115. doi: 10.2147/AABC.S301488

Garcia, S. S., Blackledge, M. S., Michalek, S., Su, L., Ptacek, T., Eipers, P., et al. (2017). Targeting of Streptococcus Mutans Biofilms by a Novel Small Molecule Prevents Dental Caries and Preserves the Oral Microbiome. J. Dent. Res. 96 (7), 807-814. doi: 10.1177/0022034517698096

Gürsu, B. Y. (2020). Potential Antibiofilm Activity of Farnesol-Loaded Poly (DLLactide-Co-Glycolide)(PLGA) Nanoparticles Against Candida Albicans. J. Anal. Sci. Technol. Health Care 11 (1), 1-10.

Hairul Islam, M. I., Arokiyaraj, S., Kuralarasan, M., Senthil Kumar, V., Harikrishnan, P., Saravanan, S., et al. (2020). Inhibitory Potential of EGCG on Streptococcus Mutans Biofilm: A New Approach to Prevent Cariogenesis. Microb. Pathog. 143, 104129. doi: 10.1016/j.micpath.2020.104129

Hajishengallis, G. (2015). Periodontitis: From Microbial Immune Subversion to Systemic Inflammation. Nat. Rev. Immunol. 15 (1), 30-44. doi: 10.1038/ nri3785

Hajishengallis, G., Darveau, R. P., and Curtis, M. A. (2012). The KeystonePathogen Hypothesis. Nat. Rev. Microbiol. 10 (10), 717-725. doi: 10.1038/ nrmicro2873

Hajishengallis, G., and Lamont, R. J. (2012). Beyond the Red Complex and Into More Complexity: The Polymicrobial Synergy and Dysbiosis (PSD) Model of Periodontal Disease Etiology. Mol. Oral. Microbiol. 27 (6), 409-419. doi: 10.1111/j.2041-1014.2012.00663.x

Hamada, S., Koga, T., and Ooshima, T. (1984). Virulence Factors of Streptococcus Mutans and Dental Caries Prevention. J. Dent. Res. 63 (3), 407-411. doi: $10.1177 / 00220345840630031001$

Hao, W., Qiao, D., Han, Y., Du, N., Li, X., Fan, Y., et al. (2021). Identification of Disulfiram as a Potential Antifungal Drug by Screening Small Molecular Libraries. J. Infect. Chemother. 27 (5), 696-701. doi: 10.1016/j.jiac.2020.12.012

Havarstein, L. S., Diep, D. B., and Nes, I. F. (1995). A Family of Bacteriocin ABC Transporters Carry Out Proteolytic Processing of Their Substrates Concomitant With Export. Mol. Microbiol. 16 (2), 229-240. doi: 10.1111/ j.1365-2958.1995.tb02295.x

He, Z. Y., Zhang, X., Song, Z. C., Li, L., Chang, H. S., Li, S. L., et al. (2020). Quercetin Inhibits Virulence Properties of Porphyromas Gingivalis in Periodontal Disease. Sci. Rep. 10 (1), 18313. doi: 10.1038/s41598-020-74977-y

Hegstad, K., Langsrud, S., Lunestad, B. T., Scheie, A. A., Sunde, M., and Yazdankhah, S. P. (2010). Does the Wide Use of Quaternary Ammonium Compounds Enhance the Selection and Spread of Antimicrobial Resistance and Thus Threaten Our Health? Microb. Drug Resist. 16 (2), 91-104. doi: $10.1089 / \mathrm{mdr} .2009 .0120$

Holmes, A. R., Cardno, T. S., Strouse, J. J., Ivnitski-Steele, I., Keniya, M. V., Lackovic, K., et al. (2016). Targeting Efflux Pumps to Overcome Antifungal Drug Resistance. Future Med. Chem. 8 (12), 1485-1501. doi: 10.4155/fmc2016-0050

Hoyer, L. L. (2001). The ALS Gene Family of Candida Albicans. Trends Microbiol. 9 (4), 176-180. doi: 10.1016/S0966-842X(01)01984-9
Ishii, S., Fukui, K., Yokoshima, S., Kumagai, K., Beniyama, Y., Kodama, T., et al. (2017). High-Throughput Screening of Small Molecule Inhibitors of the Streptococcus Quorum-Sensing Signal Pathway. Sci. Rep. 7 (1), 4029. doi: 10.1038/s41598-017-03567-2

Iyer, K. R., Camara, K., Daniel-Ivad, M., Trilles, R., Pimentel-Elardo, S. M., Fossen, J. L., et al. (2020). An Oxindole Efflux Inhibitor Potentiates Azoles and Impairs Virulence in the Fungal Pathogen Candida Auris. Nat. Commun. 11 (1), 6429. doi: 10.1038/s41467-020-20183-3

Jabir, M. S., Taha, A. A., and Sahib, U. I. (2018). Linalool Loaded on GlutathioneModified Gold Nanoparticles: A Drug Delivery System for a Successful Antimicrobial Therapy. Artif. Cells Nanomedicine Biotechnol. Adv. 46 (sup2), 345-355. doi: 10.1080/21691401.2018.1457535

Jahanizadeh, S., Yazdian, F., Marjani, A., Omidi, M., and Rashedi, H. (2017). Curcumin-Loaded Chitosan/Carboxymethyl Starch/Montmorillonite BioNanocomposite for Reduction of Dental Bacterial Biofilm Formation. Int. J. Biol. Macromol. 105, 757-763. doi: 10.1016/j.ijbiomac.2017.07.101

Jenkinson, H. F., and Demuth, D. R. (1997). Structure, Function and Immunogenicity of Streptococcal Antigen I/II Polypeptides. Mol. Microbiol. 23 (2), 183-190. doi: 10.1046/j.1365-2958.1997.2021577.x

Jeon, J. G., Pandit, S., Xiao, J., Gregoire, S., Falsetta, M. L., Klein, M. I., et al. (2011). Influences of Trans-Trans Farnesol, a Membrane-Targeting Sesquiterpenoid, on Streptococcus Mutans Physiology and Survival Within Mixed-Species Oral Biofilms. Int. J. Oral. Sci. 3 (2), 98-106. doi: 10.4248/IJOS11038

Jones, C. G. (1997). Chlorhexidine: Is It Still the Gold Standard? Periodontol. 2000 15, 55-62. doi: 10.1111/j.1600-0757.1997.tb00105.x.

Kalimuthu, S., Cheung, B. P. K., Yau, J. Y. Y., Shanmugam, K., Solomon, A. P., and Neelakantan, P. (2020). A Novel Small Molecule, 1,3-Di-M-Tolyl-Urea, Inhibits and Disrupts Multispecies Oral Biofilms. Microorganisms 8 (9), 1261. doi: 10.3390/microorganisms8091261

Kapoor, D. N., Bhatia, A., Kaur, R., Sharma, R., Kaur, G., and Dhawan, S. (2015). PLGA: A Unique Polymer for Drug Delivery. Ther. Deliv. 6 (1), 41-58. doi: 10.4155/tde. 14.91

Kariu, T., Nakao, R., Ikeda, T., Nakashima, K., Potempa, J., and Imamura, T. (2017). Inhibition of Gingipains and Porphyromonas Gingivalis Growth and Biofilm Formation by Prenyl Flavonoids. J. Periodontal. Res. 52 (1), 89-96. doi: $10.1111 /$ jre. 12372

Kathwate, G. H., Shinde, R. B., and Mohan Karuppayil, S. (2021). Non-Antifungal Drugs Inhibit Growth, Morphogenesis and Biofilm Formation in Candida Albicans. J. Antibiot. (Tokyo) 74 (5), 346-353. doi: 10.1038/s41429-020-00403-0

Kaur, G., Balamurugan, P., and Princy, S. A. (2017). Inhibition of the Quorum Sensing System (ComDE Pathway) by Aromatic 1,3-Di-M-Tolylurea (DMTU): Cariostatic Effect With Fluoride in Wistar Rats. Front. Cell Infect. Microbiol. 7, 313. doi: $10.3389 /$ fcimb. 2017.00313

Kaur, G., Balamurugan, P., Uma Maheswari, C., Anitha, A., and Princy, S. A. (2016). Combinatorial Effects of Aromatic 1,3-Disubstituted Ureas and Fluoride on In Vitro Inhibition of Streptococcus Mutans Biofilm Formation. Front. Microbiol. 7, 861. doi: 10.3389/fmicb.2016.00861

Kelly, C. G., Younson, J. S., Hikmat, B. Y., Todryk, S. M., Czisch, M., Haris, P. I., et al. (1999). A Synthetic Peptide Adhesion Epitope as a Novel Antimicrobial Agent. Nat. Biotechnol. 17 (1), 42-47. doi: 10.1038/5213

Keniya, M. V., Fleischer, E., Klinger, A., Cannon, R. D., and Monk, B. C. (2015). Inhibitors of the Candida Albicans Major Facilitator Superfamily Transporter Mdr1p Responsible for Fluconazole Resistance. PloS One 10 (5), e0126350. doi: 10.1371/journal.pone.0126350

Kett, S., Pathak, A., Turillazzi, S., Cavalieri, D., and Marvasi, M. (2021). Antifungals, Arthropods and Antifungal Resistance Prevention: Lessons From Ecological Interactions. Proc. Biol. Sci. 288 (1944), 20202716. doi: 10.1098/rspb.2020.2716

Kim, S., Song, M., Roh, B. D., Park, S. H., and Park, J. W. (2013). Inhibition of Streptococcus Mutans Biofilm Formation on Composite Resins Containing Ursolic Acid. Restor. Dent. Endod. 38 (2), 65-72. doi: 10.5395/rde.2013.38.2.65

Kim, D., Barraza, J. P., Arthur, R. A., Hara, A., Lewis, K., Liu, Y., et al. (2020). Spatial Mapping of Polymicrobial Communities Reveals a Precise Biogeography Associated With Human Dental Caries. Proc. Natl. Acad. Sci. U.S.A. 117 (22), 12375-12386. doi: 10.1073/pnas.1919099117

Kim, K., Kim, D., Lee, H., Lee, T. H., Kim, K. Y., and Kim, H. (2020). New Pyrimidinone-Fused 1,4-Naphthoquinone Derivatives Inhibit the Growth of Drug Resistant Oral Bacteria. Biomedicines 8 (6), 160. doi: 10.3390/ biomedicines 8060160 
Kojima, T., Yasui, S., and Ishikawa, I. (1993). Distribution of Porphyromonas Gingivalis in Adult Periodontitis Patients. J. Periodontol. 64 (12), 1231-1237. doi: 10.1902/jop.1993.64.12.1231

Kolouchova, I., Matatkova, O., Paldrychova, M., Kodes, Z., Kvasnickova, E., Sigler, K., et al. (2018). Resveratrol, Pterostilbene, and Baicalein: Plant-Derived AntiBiofilm Agents. Folia Microbiol. (Praha) 63 (3), 261-272. doi: 10.1007/s12223017-0549-0

Koo, H., Rosalen, P. L., Cury, J. A., Park, Y. K., and Bowen, W. H. (2002). Effects of Compounds Found in Propolis on Streptococcus Mutans Growth and on Glucosyltransferase Activity. Antimicrob. Agents Chemother. 46 (5), 13021309. doi: 10.1128/AAC.46.5.1302-1309.2002

Koo, H., Hayacibara, M. F., Schobel, B. D., Cury, J. A., Rosalen, P. L., Park, Y. K., et al. (2003). Inhibition of Streptococcus Mutans Biofilm Accumulation and Polysaccharide Production by Apigenin and Tt-Farnesol. J. Antimicrob. Chemother. 52 (5), 782-789. doi: 10.1093/jac/dkg449

Koo, H., Schobel, B., Scott-Anne, K., Watson, G., Bowen, W. H., Cury, J. A., et al. (2005). Apigenin and Tt-Farnesol With Fluoride Effects on S. Mutans Biofilms and Dental Caries. J. Dent. Res. 84 (11), 1016-1020. doi: 10.1177/154405910508401109

Krom, B. P., Kidwai, S., and Ten Cate, J. M. (2014). Candida and Other Fungal Species: Forgotten Players of Healthy Oral Microbiota. J. Dent. Res. 93 (5), 445451. doi: 10.1177/0022034514521814

Krzysciak, W., Jurczak, A., Koscielniak, D., Bystrowska, B., and Skalniak, A. (2014). The Virulence of Streptococcus Mutans and the Ability to Form Biofilms. Eur. J. Clin. Microbiol. Infect. Dis. 33 (4), 499-515. doi: 10.1007/ s10096-013-1993-7

Kuang, X., Yang, T., Zhang, C., Peng, X., Ju, Y., Li, C., et al. (2020). Repurposing Napabucasin as an Antimicrobial Agent Against Oral Streptococcal Biofilms. BioMed. Res. Int. 2020, 8379526. doi: 10.1155/2020/8379526

Kuete, V., Eyong, K. O., Folefoc, G. N., Beng, V. P., Hussain, H., Krohn, K., et al. (2007). Antimicrobial Activity of the Methanolic Extract and of the Chemical Constituents Isolated From Newbouldia Laevis. Pharmazie 62 (7), 552-556.

Kuete, V., Alibert-Franco, S., Eyong, K. O., Ngameni, B., Folefoc, G. N., Nguemeving, J. R., et al. (2011). Antibacterial Activity of Some Natural Products Against Bacteria Expressing a Multidrug-Resistant Phenotype. Int. J. Antimicrob. Agents 37 (2), 156-161. doi: 10.1016/j.ijantimicag.2010.10.020

Kugaji, M. S., Kumbar, V. M., Peram, M. R., Patil, S., Bhat, K. G., and Diwan, P. V. (2019). Effect of Resveratrol on Biofilm Formation and Virulence Factor Gene Expression of Porphyromonas Gingivalis in Periodontal Disease. APMIS 127 (4), 187-195. doi: 10.1111/apm.12930

Kumar, A., and Balbach, J. (2017). Targeting the Molecular Chaperone SlyD to Inhibit Bacterial Growth With a Small Molecule. Sci. Rep. 7, 42141. doi: $10.1038 /$ srep42141

Lee, S. F., and Boran, T. L. (2003). Roles of Sortase in Surface Expression of the Major Protein Adhesin P1, Saliva-Induced Aggregation and Adherence, and Cariogenicity of Streptococcus Mutans. Infect. Immun. 71 (2), 676-681. doi: 10.1128/IAI.71.2.676-681.2003

Li, L., Zhang, T., Xu, J., Wu, J., Wang, Y., Qiu, X., et al. (2019). The Synergism of the Small Molecule ENOblock and Fluconazole Against Fluconazole-Resistant Candida Albicans. Front. Microbiol. 10, 2071. doi: 10.3389/fmicb.2019.02071

Li, Y., Gao, S., Shi, S., Xiao, D., Peng, S., Gao, Y., et al. (2021). Tetrahedral Framework Nucleic Acid-Based Delivery of Resveratrol Alleviates Insulin Resistance: From Innate to Adaptive Immunity. Nano-Micro. Lett. 13 (1), 86. doi: 10.1007/s40820-021-00711-6

Lim, K. S., and Kam, P. C. (2008). Chlorhexidine-Pharmacology and Clinical Applications. Anaesth. Intensive Care 36 (4), 502-512. doi: 10.1177/ 0310057X0803600404

Liu, C., Worthington, R. J., Melander, C., and Wu, H. (2011). A New Small Molecule Specifically Inhibits the Cariogenic Bacterium Streptococcus Mutans in Multispecies Biofilms. Antimicrob. Agents Chemother. 55 (6), 2679-2687. doi: 10.1128/AAC.01496-10

Li, M. Y., Wang, J., and Lai, G. Y. (2009). Effect of a Dentifrice Containing the Peptide of Streptococcal Antigen I/II on the Adherence of Mutans Streptococcus. Arch. Oral. Biol. 54 (11), 1068-1073. doi: 10.1016/ j.archoralbio.2009.08.004

Lohse, M. B., Ennis, C. L., Hartooni, N., Johnson, A. D., and Nobile, C. J. (2018). Development and Regulation of Single- and Multi-Species Candida Albicans Biofilms. Nat. Rev. Microbiol. 16 (1), 19-31. doi: 10.1038/nrmicro.2017.107
Lohse, M. B., Gulati, M., Johnson, A. D., and Nobile, C. J. (2020). A Screen for Small Molecules to Target Candida Albicans Biofilms. J. Fungi (Basel) 7 (1), 9. doi: 10.3390/jof7010009

Love, R. M., McMillan, M. D., and Jenkinson, H. F. (1997). Invasion of Dentinal Tubules by Oral Streptococci Is Associated With Collagen Recognition Mediated by the Antigen I/II Family of Polypeptides. Infect. Immun. 65 (12), 5157-5164. doi: 10.1128/iai.65.12.5157-5164.1997

Lyu, X., Li, C., Zhang, J., Wang, L., Jiang, Q., Shui, Y., et al. (2021a). A Novel Small Molecule, LCG-N25, Inhibits Oral Streptococcal Biofilm. Front. Microbiol. 12, 654692. doi: 10.3389/fmicb.2021.654692

Lyu, X., Wang, L., Shui, Y., Jiang, Q., Chen, L., Yang, W., et al. (2021b). Ursolic Acid Inhibits Multi-Species Biofilms Developed by Streptococcus Mutans, Streptococcus Sanguinis, and Streptococcus Gordonii. Arch. Oral. Biol. 125, 105107. doi: 10.1016/j.archoralbio.2021.105107

Maeda, K., Nagata, H., Yamamoto, Y., Tanaka, M., Tanaka, J., Minamino, N., et al. (2004). Glyceraldehyde-3-Phosphate Dehydrogenase of Streptococcus Oralis Functions as a Coadhesin for Porphyromonas Gingivalis Major Fimbriae. Infect. Immun. 72 (3), 1341-1348. doi: 10.1128/IAI.72.3.1341-1348.2004

Maghsoudi, A., Yazdian, F., Shahmoradi, S., Ghaderi, L., Hemati, M., and Amoabediny, G. (2017). Curcumin-Loaded Polysaccharide Nanoparticles: Optimization and Anticariogenic Activity Against Streptococcus Mutans. Mater. Sci. Eng.: C 75, 1259-1267. doi: 10.1016/j.msec.2017.03.032

Marsh, P. D. (2010). Microbiology of Dental Plaque Biofilms and Their Role in Oral Health and Caries. Dent. Clin. North Am. 54 (3), 441-454. doi: 10.1016/ j.cden.2010.03.002

Mayer, F. L., Wilson, D., and Hube, B. (2013). Candida Albicans Pathogenicity Mechanisms. Virulence 4 (2), 119-128. doi: 10.4161/viru.22913

Melok, A. L. (2018). Green Tea Polyphenol Epigallocatechin-3-Gallate-Stearate Inhibits the Growth of Streptococcus Mutans: A Promising New Approach in Caries Prevention. Dent. J. (Basel) 6 (3), 38. doi: 10.3390/dj6030038

Menzel, L. P., Chowdhury, H. M., Masso-Silva, J. A., Ruddick, W., Falkovsky, K., Vorona, R., et al. (2017). Potent In Vitro and In Vivo Antifungal Activity of a Small Molecule Host Defense Peptide Mimic Through a Membrane-Active Mechanism. Sci. Rep. 7 (1), 4353. doi: 10.1038/s41598-017-04462-6

Metwalli, K. H., Khan, S. A., Krom, B. P., and Jabra-Rizk, M. A. (2013). Streptococcus Mutans, Candida Albicans, and the Human Mouth: A Sticky Situation. PloS Pathog. 9 (10), e1003616. doi: 10.1371/journal.ppat. 1003616

Mir, M., Ahmed, N., and ur Rehman, A. (2017). Recent Applications of PLGA Based Nanostructures in Drug Delivery. Colloids Surf. B: Biointerfaces 159, 217-231. doi: 10.1016/j.colsurfb.2017.07.038

Mizukami, S., Kashibe, M., Matsumoto, K., Hori, Y., and Kikuchi, K. (2017). Enzyme-Triggered Compound Release Using Functionalized Antimicrobial Peptide Derivatives. Chem. Sci. (Royal Soc. Chem.: 2010) 8 (4), 3047-3053. doi: 10.1039/c6sc04435b

Munro, G. H., Evans, P., Todryk, S., Buckett, P., Kelly, C. G., and Lehner, T. (1993). A Protein Fragment of Streptococcal Cell Surface Antigen I/II Which Prevents Adhesion of Streptococcus Mutans. Infect. Immun. 61 (11), 45904598. doi: 10.1128/iai.61.11.4590-4598.1993

Murciano, C., Moyes, D. L., Runglall, M., Tobouti, P., Islam, A., Hoyer, L. L., et al. (2012). Evaluation of the Role of Candida Albicans Agglutinin-Like Sequence (Als) Proteins in Human Oral Epithelial Cell Interactions. PloS One 7 (3), e33362. doi: 10.1371/journal.pone.0033362

Nakanishi-Matsui, M., Sekiya, M., and Futai, M. (2016). ATP Synthase From Escherichia Coli: Mechanism of Rotational Catalysis, and Inhibition With the Epsilon Subunit and Phytopolyphenols. Biochim. Biophys. Acta 1857 (2), 129140. doi: 10.1016/j.bbabio.2015.11.005

Newman, D. J., and Cragg, G. M. (2020). Natural Products as Sources of New Drugs Over the Nearly Four Decades From 01/1981 to 09/2019. J. Nat. Prod. 83 (3), 770-803. doi: 10.1021/acs.jnatprod.9b01285

Nicolosi, D., Cupri, S., Genovese, C., Tempera, G., Mattina, R., and Pignatello, R. (2015). Nanotechnology Approaches for Antibacterial Drug Delivery: Preparation and Microbiological Evaluation of Fusogenic Liposomes Carrying Fusidic Acid. Int. J. Antimicrobial. Agents 45 (6), 622-626. doi: 10.1016/j.ijantimicag.2015.01.016

Nijampatnam, B., Zhang, H., Cai, X., Michalek, S. M., Wu, H., and Velu, S. E. (2018). Inhibition of Streptococcus Mutans Biofilms by the Natural Stilbene 
Piceatannol Through the Inhibition of Glucosyltransferases. ACS Omega 3 (7), 8378-8385. doi: 10.1021/acsomega.8b00367

Nijampatnam, B., Ahirwar, P., Pukkanasut, P., Womack, H., Casals, L., Zhang, H., et al. (2021). Discovery of Potent Inhibitors of Streptococcus Mutans Biofilm With Antivirulence Activity. ACS Med. Chem. Lett. 12 (1), 48-55. doi: 10.1021/ acsmedchemlett.0c00373

Niu, Y., Wang, K., Zheng, S., Wang, Y., Ren, Q., Li, H., et al. (2020). Antibacterial Effect of Caffeic Acid Phenethyl Ester on Cariogenic Bacteria and Streptococcus Mutans Biofilms. Antimicrob. Agents Chemother. 64 (9), e00251-20. doi: 10.1128/AAC.00251-20

Padder, S. A., Prasad, R., and Shah, A. H. (2018). Quorum Sensing: A Less Known Mode of Communication Among Fungi. Microbiol. Res. 210, 51-58. doi: 10.1016/j.micres.2018.03.007

Pagniez, F., Lebouvier, N., Na, Y. M., Ourliac-Garnier, I., Picot, C., Le Borgne, M., et al. (2020). Biological Exploration of a Novel 1,2,4-Triazole-Indole Hybrid Molecule as Antifungal Agent. J. Enzyme Inhib. Med. Chem. 35 (1), 398-403. doi: 10.1080/14756366.2019.1705292

Papenfort, K., and Bassler, B. L. (2016). Quorum Sensing Signal-Response Systems in Gram-Negative Bacteria. Nat. Rev. Microbiol. 14 (9), 576-588. doi: 10.1038/ nrmicro.2016.89

Park, Y., Simionato, M. R., Sekiya, K., Murakami, Y., James, D., Chen, W., et al. (2005). Short Fimbriae of Porphyromonas Gingivalis and Their Role in Coadhesion With Streptococcus Gordonii. Infect. Immun. 73 (7), 3983-3989. doi: 10.1128/IAI.73.7.3983-3989.2005

Park, W., Ahn, C. H., Cho, H., Kim, C. K., Shin, J., and Oh, K. B. (2017). Inhibitory Effects of Flavonoids From Spatholobus Suberectus on Sortase A and Sortase A-Mediated Aggregation of Streptococcus Mutans. J. Microbiol. Biotechnol. 27 (8), 1457-1460. doi: 10.4014/jmb.1704.04001

Park, J. S., Ryu, E. J., Li, L., Choi, B. K., and Kim, B. M. (2017). New Bicyclic Brominated Furanones as Potent Autoinducer-2 Quorum-Sensing Inhibitors Against Bacterial Biofilm Formation. Eur. J. Med. Chem. 137, 76-87. doi: 10.1016/j.ejmech.2017.05.037

Patil, P. C., Tan, J., Demuth, D. R., and Luzzio, F. A. (2016). 1,2,3-Triazole-Based Inhibitors of Porphyromonas Gingivalis Adherence to Oral Streptococci and Biofilm Formation. Bioorg. Med. Chem. 24 (21), 5410-5417. doi: 10.1016/j.bmc.2016.08.059

Patil, P. C., Tan, J., Demuth, D. R., and Luzzio, F. A. (2019). 'Second-Generation' 1,2,3-Triazole-Based Inhibitors of Porphyromonas Gingivalis Adherence to Oral Streptococci and Biofilm Formation. Medchemcomm. 10 (2), 268-279. doi: $10.1039 / \mathrm{c} 8 \mathrm{md} 00405 \mathrm{f}$

Peters, B. M., Ovchinnikova, E. S., Krom, B. P., Schlecht, L. M., Zhou, H., Hoyer, L. L., et al. (2012). Staphylococcus Aureus Adherence to Candida Albicans Hyphae Is Mediated by the Hyphal Adhesin Als3p. Microbiol. (Read.) 158 (Pt 12), 2975-2986. doi: 10.1099/mic.0.062109-0

Rai, M., Ingle, A. P., Pandit, R., Paralikar, P., Gupta, I., Chaud, M. V., et al. (2017). Broadening the Spectrum of Small-Molecule Antibacterials by Metallic Nanoparticles to Overcome Microbial Resistance. Int. J. Pharm. 532 (1), 139-148. doi: 10.1016/j.ijpharm.2017.08.127

Rath, S. K., and Singh, M. (2013). Comparative Clinical and Microbiological Efficacy of Mouthwashes Containing $0.2 \%$ and $0.12 \%$ Chlorhexidine. Dent. Res. J. (Isfahan) 10 (3), 364-369.

Ren, Z., Cui, T., Zeng, J., Chen, L., Zhang, W., Xu, X., et al. (2016). Molecule Targeting Glucosyltransferase Inhibits Streptococcus Mutans Biofilm Formation and Virulence. Antimicrob. Agents Chemother. 60 (1), 126-135. doi: 10.1128/AAC.00919-15

Riep, B., Edesi-Neuss, L., Claessen, F., Skarabis, H., Ehmke, B., Flemmig, T. F., et al. (2009). Are Putative Periodontal Pathogens Reliable Diagnostic Markers? J. Clin. Microbiol. 47 (6), 1705-1711. doi: 10.1128/JCM.01387-08

Rivera-Quiroga, R. E., Cardona, N.m, Padilla, L., Rivera, W., Rocha-Roa, C., and Diaz De Rienzo, M. A.. (2020). In Silico Selection and In Vitro Evaluation of New Molecules That Inhibit the Adhesion of Streptococcus Mutants Through Antigen I/II. Int. J. Mol. Sci. 22 (1),377. doi: 10.3390/ijms22010377

Roky, M., Tan, J., Sztukowska, M. N., Trent, J. O., and Demuth, D. R. (2020). Identification of Small-Molecule Inhibitors Targeting Porphyromonas Gingivalis Interspecies Adherence and Determination of Their In Vitro and In Vivo Efficacies. Antimicrob. Agents Chemother. 64 (11), e00884-20. doi: 10.1128/AAC.00884-20

Ryan, L. K., Freeman, K. B., Masso-Silva, J. A., Falkovsky, K., Aloyouny, A., Markowitz, K., et al. (2014). Activity of Potent and Selective Host Defense
Peptide Mimetics in Mouse Models of Oral Candidiasis. Antimicrobial. Agents Chemother. 58 (7), 3820-3827. doi: 10.1128/AAC.02649-13

Ryu, E. J., Sim, J., Sim, J., Lee, J., and Choi, B. K. (2016). D-Galactose as an Autoinducer 2 Inhibitor to Control the Biofilm Formation of Periodontopathogens. J. Microbiol. 54 (9), 632-637. doi: 10.1007/s12275-016-6345-8

Salmanli, M., Tatar Yilmaz, G., and Tuzuner, T. (2021). Investigation of the Antimicrobial Activities of Various Antimicrobial Agents on Streptococcus Mutans Sortase A Through Computer-Aided Drug Design (CADD) Approaches. Comput. Methods Programs BioMed. 212, 106454. doi: 10.1016/ j.cmpb.2021.106454

Samad, A., Sultana, Y., and Aqil, M. (2007). Liposomal Drug Delivery Systems: An Update Review. Curr. Drug Deliv. 4 (4), 297-305. doi: 10.2174/ 156720107782151269

Samaranayake, L., and Matsubara, V. H. (2017). Normal Oral Flora and the Oral Ecosystem. Dent. Clin. North Am. 61 (2), 199-215. doi: 10.1016/j.cden.2016.11.002

Saputo, S., Faustoferri, R. C., and Quivey, R. G. Jr. (2018). Vitamin D Compounds Are Bactericidal Against Streptococcus Mutans and Target the BacitracinAssociated Efflux System. Antimicrob. Agents Chemother. 62 (1), e01675-17. doi: 10.1128/AAC.01675-17

Sekiya, M., Chiba, E., Satoh, M., Yamakoshi, H., Iwabuchi, Y., Futai, M., et al. (2014). Strong Inhibitory Effects of Curcumin and Its Demethoxy Analog on Escherichia Coli ATP Synthase F1 Sector. Int. J. Biol. Macromol. 70, 241-245. doi: 10.1016/j.ijbiomac.2014.06.055

Sekiya, M., Izumisawa, S., Iwamoto-Kihara, A., Fan, Y., Shimoyama, Y., Sasaki, M., et al. (2019). Proton-Pumping F-ATPase Plays an Important Role in Streptococcus Mutans Under Acidic Conditions. Arch. Biochem. Biophys. 666, 46-51. doi: 10.1016/j.abb.2019.03.014

Shao, H., and Demuth, D. R. (2010). Quorum Sensing Regulation of Biofilm Growth and Gene Expression by Oral Bacteria and Periodontal Pathogens. Periodontol. 2000 52 (1), 53-67. doi: 10.1111/j.1600-0757.2009.00318.x

Shinobu-Mesquita, C. S., Martins, E., Junior, J. B., de Souza Bonfim-Mendonca, P., Felipe, M. S. S., Kioshima, E. S., et al. (2020). In Vitro and In Vivo Activity of a Possible Novel Antifungal Small Molecule Against Candida Albicans. J. Mycol. Med. 30 (2), 100939. doi: 10.1016/j.mycmed.2020.100939

Silva, A. R., Santos, E. B., Pinto, S. C., Gomes, J. C., Vaz, I. P., and Carvalho, M. F. (2014). Antimicrobial Effect and Transdentinal Diffusion of New Intracanal Formulations Containing Nitrofurantoin or Doxycycline. Braz. Dent. J. 25 (5), 425-429. doi: 10.1590/0103-6440201302338

Singh, A. K., Yadav, S., Sharma, K., Firdaus, Z., Aditi, P., Neogi, K., et al. (2019). Quantum Curcumin Mediated Inhibition of Gingipains and Mixed-Biofilm of Porphyromonas Gingivalis Causing Chronic Periodontitis (Vol 82018). Rsc. Adv. 9 (1), 91-91, pg 40426. doi: 10.1039/c8ra90104j

Socransky, S. S., Haffajee, A. D., Cugini, M. A., Smith, C., and Kent, R. L.Jr. (1998). Microbial Complexes in Subgingival Plaque. J. Clin. Periodontol. 25 (2), 134144. doi: 10.1111/j.1600-051X.1998.tb02419.x

Song, M., Teng, Z., Li, M., Niu, X., Wang, J., and Deng, X. (2017). Epigallocatechin Gallate Inhibits Streptococcus Pneumoniae Virulence by Simultaneously Targeting Pneumolysin and Sortase A. J. Cell Mol. Med. 21 (10), 2586-2598. doi: $10.1111 / \mathrm{jcmm} .13179$

Staniszewska, M., Kuryk, L., Gryciuk, A., Kawalec, J., Rogalska, M., Baran, J., et al. (2021a). In Vitro Anti-Candida Activity and Action Mode of Benzoxazole Derivatives. Molecules 26 (16), 5008. doi: 10.3390/molecules26165008

Staniszewska, M., Kuryk, L., Gryciuk, A., Kawalec, J., Rogalska, M., Baran, J., et al. (2021b). The Antifungal Action Mode of N-Phenacyldibromobenzimidazoles. Molecules 26 (18), 5463. doi: 10.3390/molecules 26185463

Stavroullakis, A. T., Goncalves, L. L., Levesque, C. M., Kishen, A., and Prakki, A. (2021). Interaction of Epigallocatechin-Gallate and Chlorhexidine With Streptococcus Mutans Stimulated Odontoblast-Like Cells: Cytotoxicity, Interleukin-1beta and Co-Species Proteomic Analyses. Arch. Oral. Biol. 131, 105268. doi: 10.1016/j.archoralbio.2021.105268

Sun, Y., Li, S., Zhang, Y., Li, Q., Xie, X., Zhao, D., et al. (2020). Tetrahedral Framework Nucleic Acids Loading Ampicillin Improve the Drug Susceptibility Against Methicillin-Resistant Staphylococcus Aureus. ACS Appl. Mater. Interfaces 12 (33), 36957-36966. doi: 10.1021/acsami.0c11249

Taddei, M., Ferrini, S., Giannotti, L., Corsi, M., Manetti, F., Giannini, G., et al. (2014). Synthesis and Evaluation of New Hsp90 Inhibitors Based on a 1,4,5Trisubstituted 1,2,3-Triazole Scaffold. J. Med. Chem. 57 (6), 2258-2274. doi: $10.1021 / \mathrm{jm} 401536 \mathrm{~b}$ 
Tan, J., Patil, P. C., Luzzio, F. A., and Demuth, D. R. (2018). In Vitro and In Vivo Activity of Peptidomimetic Compounds That Target the Periodontal Pathogen Porphyromonas Gingivalis. Antimicrob. Agents Chemother. 62 (7), e00400*18. doi: 10.1128/AAC.00400-18

Tanner, A. C., Kressirer, C. A., and Faller, L. L. (2016). Understanding Caries From the Oral Microbiome Perspective. J. Calif. Dent. Assoc. 44 (7), 437-446.

Theilade, E. (1986). The Non-Specific Theory in Microbial Etiology of Inflammatory Periodontal Diseases. J. Clin. Periodontol. 13 (10), 905-911. doi: 10.1111/j.1600-051X.1986.tb01425.x

Tiwari, S., Thakur, R., and Shankar, J. (2015). Role of Heat-Shock Proteins in Cellular Function and in the Biology of Fungi. Biotechnol. Res. Int. 132635. doi: $10.1155 / 2015 / 132635$

Vediyappan, G., Dumontet, V., Pelissier, F., and d'Enfert, C. (2013). Gymnemic Acids Inhibit Hyphal Growth and Virulence in Candida Albicans. PloS One 8 (9), e74189. doi: 10.1371/journal.pone.0074189

Velaäzquez-Lam, E., Imperial, J., and Ponz, F. (2020). Polyphenol-Functionalized Plant Viral-Derived Nanoparticles Exhibit Strong Antimicrobial and Antibiofilm Formation Activities. ACS Appl. Bio Mater. 3 (4), 2040-2047. doi: 10.1021/acsabm.9b01161

Velazquez, C., Navarro, M., Acosta, A., Angulo, A., Dominguez, Z., Robles, R., et al. (2007). Antibacterial and Free-Radical Scavenging Activities of Sonoran Propolis. J. Appl. Microbiol. 103 (5), 1747-1756. doi: 10.1111/j.1365-2672.2007.03409.x

Veloz, J. J., Alvear, M., and Salazar, L. A. (2019). Antimicrobial and Antibiofilm Activity Against Streptococcus Mutans of Individual and Mixtures of the Main Polyphenolic Compounds Found in Chilean Propolis. BioMed. Res. Int. 2019, 7602343. doi: 10.1155/2019/7602343

Veloz, J. J., Saavedra, N., Alvear, M., Zambrano, T., Barrientos, L., and Salazar, L. A. (2016). Polyphenol-Rich Extract From Propolis Reduces the Expression and Activity of Streptococcus Mutans Glucosyltransferases at Subinhibitory Concentrations. BioMed. Res. Int. 2016, 4302706. doi: 10.1155/2016/4302706

Verma, D., Gulati, N., Kaul, S., Mukherjee, S., and Nagaich, U. (2018). Protein Based Nanostructures for Drug Delivery. J. Pharm. 2018, 9285854. doi: $10.1155 / 2018 / 9285854$

Walsh, T., Oliveira-Neto, J. M., and Moore, D. (2015). Chlorhexidine Treatment for the Prevention of Dental Caries in Children and Adolescents. Cochrane Database Syst. Rev. 4), CD008457. doi: 10.1002/14651858.CD008457.pub2

Wang, S., Wang, H., Ren, B., Li, H., Weir, M. D., Zhou, X., et al. (2017). Do Quaternary Ammonium Monomers Induce Drug Resistance in Cariogenic, Endodontic and Periodontal Bacterial Species? Dent. Mater. 33 (10), 11271138. doi: 10.1016/j.dental.2017.07.001

Wang, J., Shi, Y., Jing, S., Dong, H., Wang, D., and Wang, T. (2019). Astilbin Inhibits the Activity of Sortase A From Streptococcus Mutans. Molecules 24 (3), 465. doi: 10.3390/molecules24030465

Wang, L., Natan, M., Zheng, W., Zheng, W., Liu, S., Jacobi, G., et al. (2020). Small Molecule-Decorated Gold Nanoparticles for Preparing Antibiofilm Fabrics. Nanoscale Adv. 2 (6), 2293-2302. doi: 10.1039/D0NA00179A

Whitesell, L., Robbins, N., Huang, D. S., McLellan, C. A., Shekhar-Guturja, T., LeBlanc, E. V., et al. (2019). Structural Basis for Species-Selective Targeting of Hsp90 in a Pathogenic Fungus. Nat. Commun. 10 (1), 402. doi: 10.1038/ s41467-018-08248-w

Worthington, R. J., Richards, J. J., and Melander, C. (2012). Small Molecule Control of Bacterial Biofilms. Org. Biomol. Chem. 10 (37), 7457-7474. doi: $10.1039 / \mathrm{c} 2 \mathrm{ob} 25835 \mathrm{~h}$

Wright, C. J., Burns, L. H., Jack, A. A., Back, C. R., Dutton, L. C., Nobbs, A. H., et al. (2013). Microbial Interactions in Building of Communities. Mol. Oral. Microbiol. 28 (2), 83-101. doi: 10.1111/omi.12012

Wright, C. J., Wu, H., Melander, R. J., Melander, C., and Lamont, J. (2014). Disruption of Heterotypic Community Development by Porphyromonas Gingivalis With Small Molecule Inhibitors. Mol. Oral. Microbiol. 29 (5), 185-193. doi: 10.1111/omi.12060

Xu, X., Zhou, X. D., and Wu, C. D. (2011). The Tea Catechin Epigallocatechin Gallate Suppresses Cariogenic Virulence Factors of Streptococcus Mutans. Antimicrob. Agents Chemother. 55 (3), 1229-1236. doi: 10.1128/AAC.01016-10

Xu, X., Zhou, X. D., and Wu, C. D. (2012). Tea Catechin Epigallocatechin Gallate Inhibits Streptococcus Mutans Biofilm Formation by Suppressing Gtf Genes. Arch. Oral. Biol. 57 (6), 678-683. doi: 10.1016/j.archoralbio.2011.10.021

Yang, D., Pornpattananangkul, D., Nakatsuji, T., Chan, M., Carson, D., Huang, C.M., et al. (2009). The Antimicrobial Activity of Liposomal Lauric Acids Against
Propionibacterium Acnes. Biomaterials 30 (30), 6035-6040. doi: 10.1016/ j.biomaterials.2009.07.033

Yang, X., Yang, J., Wang, L., Ran, B., Jia, Y., Zhang, L., et al. (2017). Pharmaceutical Intermediate-Modified Gold Nanoparticles: Against Multidrug-Resistant Bacteria and Wound-Healing Application via an Electrospun Scaffold. ACS Nano 11 (6), 5737-5745. doi: 10.1021/acsnano.7b01240

Yin, I. X., Yu, O. Y., Zhao, I. S., Mei, M. L., Li, Q.-L., Tang, J., et al. (2019). Developing Biocompatible Silver Nanoparticles Using Epigallocatechin Gallate for Dental Use. Arch. Oral. Biol. 102, 106-112. doi: 10.1016/j.archoralbio.2019.03.022

Younson, J., and Kelly, C. (2004). The Rational Design of an Anti-Caries Peptide Against Streptococcus Mutans. Mol. Divers. 8 (2), 121-126. doi: 10.1023/B: MODI.0000025655.93643.fa

Yuan, R., Tu, J., Sheng, C., Chen, X., and Liu, N. (2021). Effects of Hsp90 Inhibitor Ganetespib on Inhibition of Azole-Resistant Candida Albicans. Front. Microbiol. 12, 680382. doi: 10.3389/fmicb.2021.680382

Yu, S., Fan, X., Zheng, S., Lin, L., Liu, J., Pan, Y., et al. (2021). The Sialidase Inhibitor, DANA, Reduces Porphyromonas Gingivalis Pathogenicity and Exerts Anti-Inflammatory Effects: An In Vitro and In Vivo Experiment. J. Periodontol. 92 (2), 286-297. doi: 10.1002/JPER.19-0688

Zazo, H., Millán, C. G., Colino, C. I., and Lanao, J. M. (2017). “Applications of Metallic Nanoparticles in Antimicrobial Therapy," in In Antimicrobial Nanoarchitectonics (Elsevier), 411-444.

Zhang, L., Kuang, X., Zhou, Y., Yang, R., Zhou, X., Peng, X., et al. (2010). Development of Nanoparticles for Antimicrobial Drug Delivery. Curr. Med. Chem. 17 (6), 585-594. doi: 10.2174/092986710790416290

Zhang, Q., Nguyen, T., McMichael, M., Velu, S. E., Zou, J., Zhou, X., et al. (2015). New Small-Molecule Inhibitors of Dihydrofolate Reductase Inhibit Streptococcus Mutans. Int. J. Antimicrob. Agents 46 (2), 174-182. doi: 10.1016/j.ijantimicag.2015.03.015

Zhang, Q., Nijampatnam, B., Hua, Z., Nguyen, T., Zou, J., Cai, X., et al. (2017). Structure-Based Discovery of Small Molecule Inhibitors of Cariogenic Virulence. Sci. Rep. 7 (1), 5974.

Zhang, Y., Ma, W., Zhu, Y., Shi, S., Li, Q., Mao, C., et al. (2018). Inhibiting Methicillin-Resistant Staphylococcus Aureus by Tetrahedral DNA Nanostructure-Enabled Antisense Peptide Nucleic Acid Delivery. Nano Lett. 18 (9), 5652-5659. doi: 10.1021/acs.nanolett.8b02166

Zhang, C., Kuang, X., Zhou, Y., Peng, X., Guo, Q., Yang, T., et al. (2019). A Novel Small Molecule, ZY354, Inhibits Dental Caries-Associated Oral Biofilms. Antimicrob. Agents Chemother. 63 (5), e02414-18. doi: 10.1128/AAC.02414-18

Zhang, T., Tian, T., Zhou, R., Li, S., Ma, W., Zhang, Y., et al. (2020). Design, Fabrication and Applications of Tetrahedral DNA Nanostructure-Based Multifunctional Complexes in Drug Delivery and Biomedical Treatment. Nat. Protoc. 15 (8), 2728-2757. doi: 10.1038/s41596-020-0355-Z

Zhang, J., Kuang, X., Zhou, Y., Yang, R., Zhou, X., Peng, X., et al. (2021). Antimicrobial Activities of a Small Molecule Compound II-6s Against Oral Streptococci. J. Oral. Microbiol. 13 (1), 1909917. doi: 10.1080/20002297.2021.1909917

Zhang, B., Qin, X., Zhou, M., Tian, T., Sun, Y., Li, S., et al. (2021). Tetrahedral DNA Nanostructure Improves Transport Efficiency and Anti-Fungal Effect of Histatin 5 Against Candida Albicans. Cell Prolif. doi: 10.1111/cpr.13020

Zhang, M., Zhang, X., Tian, T., Zhang, Q., Wen, Y., Zhu, J., et al. (2022). AntiInflammatory Activity of Curcumin-Loaded Tetrahedral Framework Nucleic Acids on Acute Gouty Arthritis. Bioact. Mater. 8, 368-380. doi: 10.1016/ j.bioactmat.2021.06.003

Zhao, Y., Tian, Y., Cui, Y., Liu, W., Ma, W., and Jiang, X. (2010). Small MoleculeCapped Gold Nanoparticles as Potent Antibacterial Agents That Target GramNegative Bacteria. J. Am. Chem. Soc. 132 (35), 12349-12356. doi: 10.1021/ ja1028843

Zhao, Y., Chen, Z., Chen, Y., Xu, J., Li, J., and Jiang, X. (2013). Synergy of nonAntibiotic Drugs and Pyrimidinethiol on Gold Nanoparticles Against Superbugs. J. Am. Chem. Soc. 135 (35), 12940-12943. doi: 10.1021/ja4058635

Conflict of Interest: The authors declare that the research was conducted in the absence of any commercial or financial relationships that could be construed as a potential conflict of interest.

Publisher's Note: All claims expressed in this article are solely those of the authors and do not necessarily represent those of their affiliated organizations, or those of the publisher, the editors and the reviewers. Any product that may be evaluated in 
this article, or claim that may be made by its manufacturer, is not guaranteed or endorsed by the publisher.

Copyright $\odot 2022$ Yang, Lyu, Zhang, Shui, Yang and Xu. This is an open-access article distributed under the terms of the Creative Commons Attribution License
(CC BY). The use, distribution or reproduction in other forums is permitted, provided the original author(s) and the copyright owner(s) are credited and that the original publication in this journal is cited, in accordance with accepted academic practice. No use, distribution or reproduction is permitted which does not comply with these terms. 